\title{
Thyroid hormone enhanced human hepatoma cell motility involves brain-specific serine protease 4 activation via ERK signaling
}

Cheng-Yi Chen ${ }^{1,2+}$, I-Hsiao Chung ${ }^{1 \dagger}$, Ming-Ming Tsai ${ }^{3}$, Yi-Hsin Tseng ${ }^{1}$, Hsiang-Cheng Chi ${ }^{1}$, Chung-Ying Tsai ${ }^{1}$, Yang-Hsiang Lin ${ }^{1}$, You-Ching Wang ${ }^{1}$, Chie-Pein Chen ${ }^{2,5}$, Tzu-I Wu' ${ }^{1}$, Chau-Ting Yeh ${ }^{4}$, Dar-In Tai ${ }^{4}$ and Kwang-Huei Lin ${ }^{1 *}$

\begin{abstract}
Background: The thyroid hormone, 3, 3', 5-triiodo-L-thyronine $\left(T_{3}\right)$, has been shown to modulate cellular processes via interactions with thyroid hormone receptors (TRs), but the secretory proteins that are regulated to exert these effects remain to be characterized. Brain-specific serine protease 4 (BSSP4), a member of the human serine protease family, participates in extracellular matrix remodeling. However, the physiological role and underlying mechanism of $\mathrm{T}_{3}$-mediated regulation of BSSP4 in hepatocellular carcinogenesis are yet to be established.

Methods: The thyroid hormone response element was identified by reporter and chromatin immunoprecipitation assays. The cell motility was analyzed via transwell and SCID mice. The BSSP4 expression in clinical specimens was examined by Western blot and quantitative reverse transcription polymerase chain reaction.

Results: Upregulation of BSSP4 at mRNA and protein levels after $T_{3}$ stimulation is a time- and dose-dependent manner in hepatoma cell lines. Additionally, the regulatory region of the BSSP4 promoter stimulated by $T_{3}$ was identified at positions -609/-594. BSSP4 overexpression enhanced tumor cell migration and invasion, both in vitro and in vivo. Subsequently, BSSP4-induced migration occurs through the ERK 1/2-C/EBP $\beta$-VEGF cascade, similar to that observed in HepG2-TRa1 and J7-TRa1 cells. BSSP4 was overexpressed in clinical hepatocellular carcinoma (HCC) patients, compared with normal subjects, and positively associated with TRa1 and VEGF to a significant extent. Importantly, a mild association between BSSP4 expression and distant metastasis was observed.

Conclusions: Our findings collectively support a potential role of $\mathrm{T}_{3}$ in cancer cell progression through regulation of the BSSP4 protease via the ERK 1/2-C/EBPB-VEGF cascade. BSSP4 may thus be effectively utilized as a novel marker and anti-cancer therapeutic target in HCC.
\end{abstract}

Keywords: Thyroid hormone receptor, Secreted protein, BSSP4, SILAC, ERK 1/2-C/EBPß-VEGF, Mmotility

\section{Introduction}

The thyroid hormone (TH) acts as a pleiotropic regulator in growth, differentiation, proliferation and other physiological processes by interacting with thyroid hormone response elements (TREs) located in the regulatory regions of target genes [1]. Indeed, TH is required to maintain the metabolic rate and oxygen consumption in almost all tissues [2]. TRs interact with the retinoid X receptor (RXR)

\footnotetext{
* Correspondence: khlin@mail.cgu.edu.tw

${ }^{\dagger}$ Equal contributors

'Department of Biochemistry, School of Medicine, Chang-Gung University, 259 Wen-hwa 1 Road, Taoyuan, Taiwan

Full list of author information is available at the end of the article
}

to form heterodimers that influence target genes by binding to their TRE regions [3]. Two TR genes, TR $\alpha$ and TR $\beta$, have been identified on human chromosomes 17 and 3, respectively. Alternative splicing and promoter usage of primary transcripts have been shown to generate TR $\alpha 1$, TR $\alpha 2, \operatorname{TR} \beta 1$ and TR $\beta 2$ receptor isoforms [4].

Previous microarray experiments by our group demonstrated that numerous genes encoding coagulation factor system components, plasma proteins, nuclear receptor coactivator, anti-metastatic proteins, proteases and oncogenes are regulated by $\mathrm{T}_{3}$ [2]. Recently, we employed stable isotope labeling with amino acids in cell culture (SILAC)based quantitative proteomic approaches, with a view to 
systematically investigating the $\mathrm{T}_{3}$-regulated secretome [5]. Consequently, several secreted proteins and the urokinase plasminogen activator (uPA) system were identified and quantified, clearly indicative of a role of $\mathrm{T}_{3}$ in the modulation of secretory proteins. Earlier proteomic analyses further revealed a significant increase in brainspecific serine protease 4 (BSSP4) involved in the uPA system [6], quantified in one of the three SILAC experiments $\left(\mathrm{T}_{3} / \mathrm{Td}>3\right)$, in $\mathrm{T}_{3}$-treated HepG2-TR $\alpha 1$ cells.

BSSP4 is a member of the human chromosome 16p13.3 serine protease family. The protease is also known as tryptase $\varepsilon$ and protease serine S1 family member 22 [7]. Previous study by Yasuda et al. [6] reported that BSSP4 catalyzes the progression of zymogen pro-uPA to active uPA. The uPA system, a serine protease family comprising tissue-type plasminogen activator (tPA), uPA, uPA receptor (UPAR) and plasminogen activator inhibitors (PAIs), is universally found in almost all cancer types [8]. While BSSP4 has been shown to play a role in different cancers [9], few studies to date have focused on its specific functions in cancer biology.

In the current study, we investigated $\mathrm{T}_{3}$-mediated regulation of BSSP4 and its underlying physiological significance in hepatoma cell lines. Our results indicate that $\mathrm{T}_{3}$-regulated BSSP4 induces cancer progression via the ERK1/2-C/EBP $\beta$-VEGF cascade in hepatoma cells. Moreover, BSSP4 is consistently overexpressed in HCC patients, compared with normal subjects, supporting its utility as a novel marker.

\section{Results}

\section{Effects of $\mathrm{T}_{3}$ on BSSP4 mRNA and protein expression}

Several isogenic HepG2 cell lines stably expressing high levels of wild-type TR $\alpha 1$ and TR $\beta 1$ (HepG2-TR $\alpha 1$ and HepG2-TR $\beta 1$, respectively) were established. Specifically, four HepG2 cell lines, HepG2-TR $\alpha 1 \# 1$, HepG2-TR $\alpha 1 \# 2$, HepG2-TR $\beta 1 \# 1$ and HepG2-Neo, and J7-TR $\alpha 1$, and parental cells expressing various levels of TR (Figure 1A) were used for analyses. Notably, BSSP4 expression was stimulated by $\mathrm{T}_{3}$ in the HepG2-TR $\alpha 1 \# 1$, HepG2-TR $\alpha 1 \# 2$ and HepG2-TR $\beta 1$ cell lines at both the mRNA (Figure 1B) and protein levels (Figure $1 \mathrm{C}$ ) in a time- and dosedependent manner. In contrast, $\mathrm{T}_{3}$ had a marginal or no effect on BSSP4 expression in HepG2-Neo cells (Figure 1B, C). Moreover, we have examined the BSSP4 regulation by $T_{3}$ in parental cells expressing endogenous TR, such as $\mathrm{J7}$ (Figure 1D, I), Huh7 (Figure 1D, II) and SK-Hep-1 cells (Additional file 1: Figure S1B). We have depleted the TR $\alpha$ and TR $\beta$ expression with siRNA in SKHep1 cell (Additional file 1: Figure S1A). The BSSP4 regulation was abolished significantly after silencing the $\mathrm{TR} \alpha$ and TR $\beta$ expression (Additional file 1: Figure S1B). Several HCC cell lines expressing low levels of endogenous TR proteins can be induced the BSSP4 expression with a lesser extent after $\mathrm{T}_{3}$ application. According to the data, we conclude the BSSP4 regulation by $\mathrm{T}_{3}$ can be observed in the parental cells as well as TR overexpression system.

\section{$\mathrm{T}_{3}$ induces BSSP4 expression at the transcriptional level}

The reporter assay was performed to determine the position of the thyroid hormone response element (TRE) to further clarify the regulatory effects of $\mathrm{T}_{3}$ on BSSP4 at the transcriptional level. The BSSP4 5'-flanking region encompassing nucleotides $-2066 /-7$ (relative to the transcription initiation site) with numerous predicted putative TREs (Figure 1E) was cloned and inserted upstream of the luciferase reporter gene in pGL2-luc (Construct p1) to generate Construct p2. The pA3TK-luc construct containing a minimum thymidine kinase promoter was designated Construct p6. Serial deletion mutants were additionally generated (Figure 1E). The transcriptional activities of the BSSP4 promoter fragments are illustrated in Figure 1E. Among these, only the p10 construct containing two putative TREs was activated about 3.5-fold by $\mathrm{T}_{3}$ in HepG2-TR $\alpha 1$ cells. The two TREs in the p10 fragment were sequentially mutated to yield p12 and p13 constructs. However, upon mutation of the other putative TRE (pal), luciferase activity of the p12 construct was completely abolished (Figure 1E). These findings suggest that $\mathrm{T}_{3}$ regulates $B S S P 4$ at the transcriptional level by binding to the putative TRE site between positions -628/-498 (p10) encompassing a pal-like sequence between positions -609 to -594 (AGGTCCTTGCTGTCCT).

TR and RXR proteins form a complex with TRE (-609 -594) within the BSSP4 promoter

To further determine whether BSSP4 TRE (pal) is directly targeted by TR proteins, the ChIP assay was performed. TR proteins were clearly associated with the TRE region of the BSSP4 promoter in vivo both HepG2-TR $\alpha 1$ and J7TR $\alpha 1$ cells (Figure 1F). Notably, TR $\alpha 1$ and RXR $\alpha$ were recruited to the TRE-binding site (Figure 1F, lanes 3, 4), whereas control IgG produced only background levels (Figure 1F, lane 2). Accordingly, we propose that the TR $\alpha 1$ and RXR $\alpha$ complexes bind to the BSSP4 promoter for transcriptional regulation.

\section{BSSP4 is associated with cancer progression in vitro}

We detected the BSSP4, TR $\alpha$ and TR $\beta$ expression in six hepatoma cell lines (Additional file 2: Figure S2). The positive correlation of BSSP 4 vs. TR $\alpha / \mathrm{TR} \beta$ expression was observed in most of the hepatoma cell lines. To determine the specific functions of BSSP4, control cell lines (Figure 2A, Huh7-control \#1 and \#2) and those overexpressing BSSP4 (Figure 2A, Huh7-BSSP4 \#1 and \#2) were established. BSSP4 has been detected in several cancer types [9]. The protein was originally identified as a member of the human serine protease family, also designated tryptase $\varepsilon$ [7]. In 
$\mathbf{A}_{\text {(I) }}$

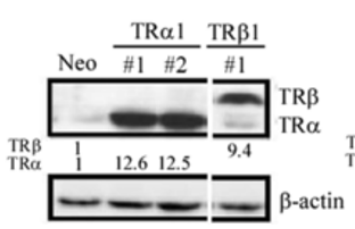

B
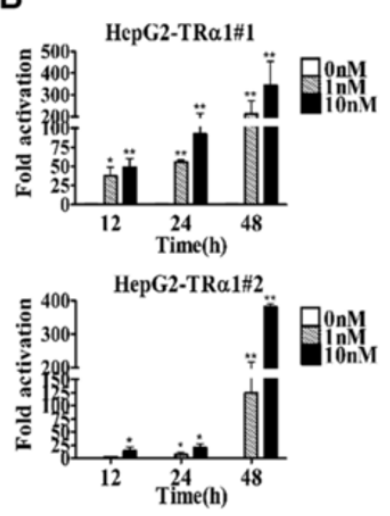

D

(I) $\mathrm{J} 7$

Time (h)

$\mathrm{T} 3(\mathrm{nM})$

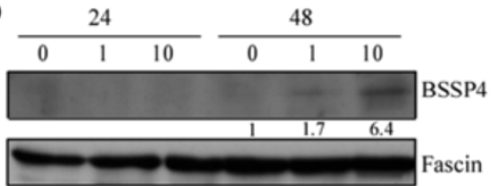

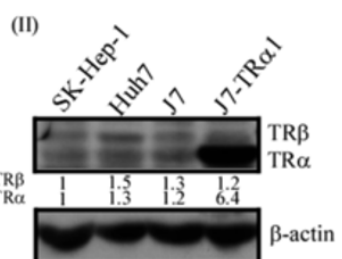
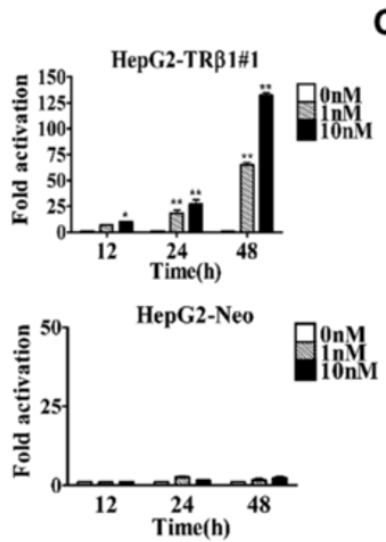

HepG2-TR $\beta 1 \# 1$

HepG2-Neo

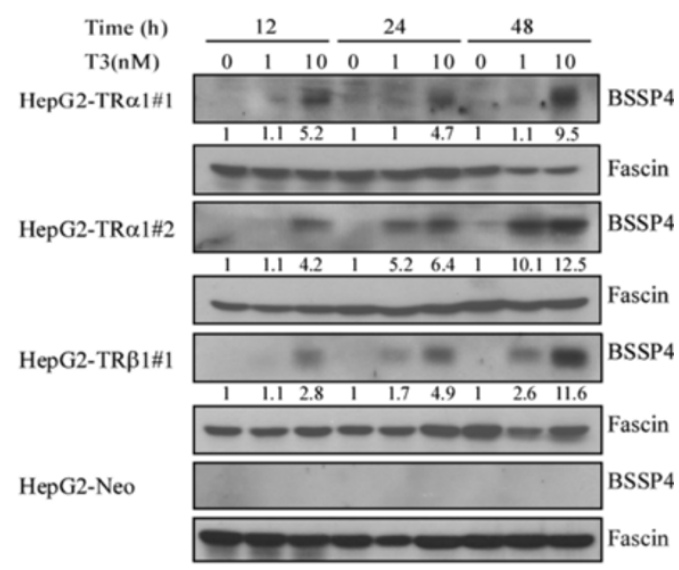

(II) $\mathrm{Huh} 7$

Time (h)

$\mathrm{T} 3(\mathrm{nM})$

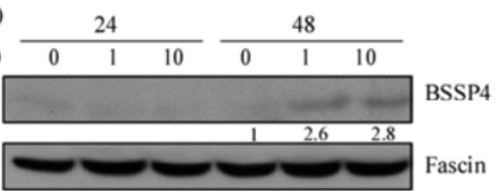

E
(p1) pGL2-Luc
(p2) $-2066 \sim 7$
(p3) $-1066 \sim 7$
(p4) $-767 \sim 7$
(p5) $-450 \sim 7$
(p6) pA3TK-Luc
(p7) $-767 \sim 350$
(p8) $-628 \sim 350$
(p9) $-767 \sim 608$
(p10) $-628 \sim-498$
(p11) $-509 \sim 350$
(p12) $-628 \sim-498$
(p13) $-628 \sim 498$

$\mathbf{F}$

HepG2-TR $\alpha$

\begin{tabular}{|c|c|c|c|c|}
\hline & Input & IgG & TR & RXR \\
\hline BSSP4(-628 -498) & cos & & & 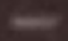 \\
\hline GAPDH & $=$ & & & . \\
\hline Furin & 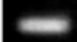 & & -20 & 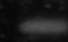 \\
\hline
\end{tabular}

DR+ pat $\square$ Imvale

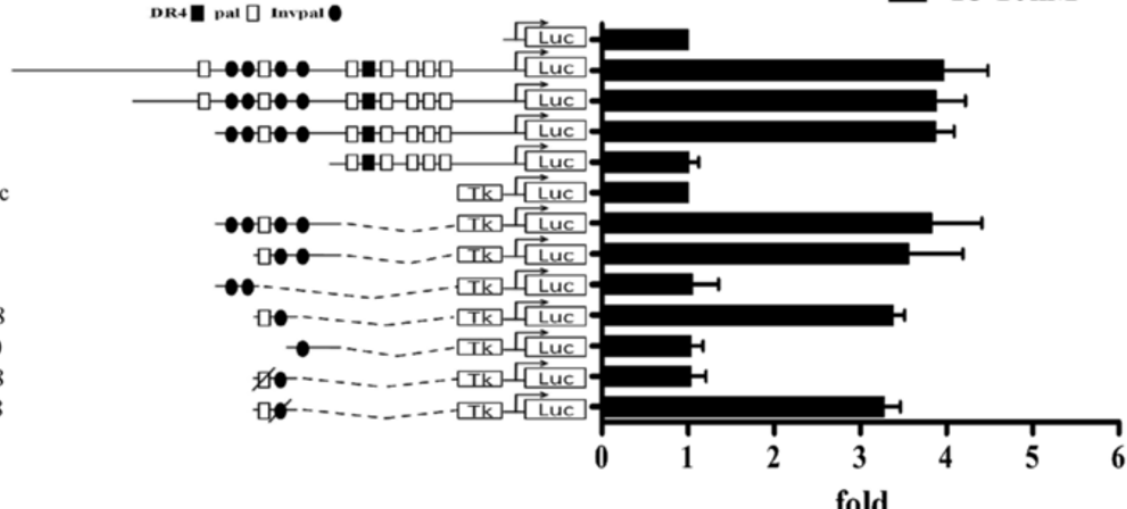

J7-TR $\alpha 1$

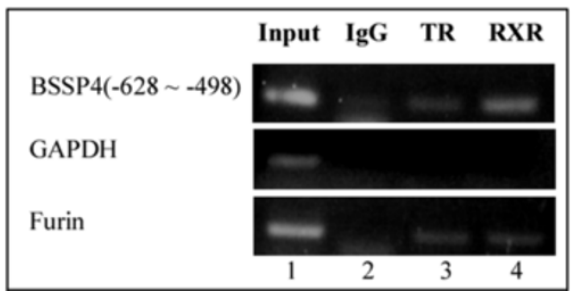

Figure 1 (See legend on next page.) 
(See figure on previous page.)

Figure $1 \mathrm{~T}_{3}$-regulates BSSP4 mRNA and protein expression in HepG2 cells. (A) Expression of TR in cell extracts of overexpressed-TR and parental cell lines was determined via Western blotting. The positions of $47 \mathrm{kDa}$ TRa1 and $55 \mathrm{kDa}$ TRß1 are indicated. BSSP4 expression was determined in the three stable HepG2-TR lines and HepG2-neo cells at 12-48 h in the absence or presence of 1 and 10 nM T3 using (B) Q-PCR and (C) Western blotting. (D) $T_{3}$ stimulated BSSP4 expression in $\mathrm{J} 7$ and Huh7 cells expressing endogenous TR was determined by Western blotting. (E) HepG2-TRa1 cells were transfected with the luciferase reporter plasmid driven by the BSSP4 5'-flanking region (positions -2066 to -7 containing twelve putative TRE sites) with or without pA3TK-luc. Promoter activities were calculated, relative to $0 \mathrm{nM} \mathrm{T}_{3}\left(+\mathrm{T}_{3} /-\mathrm{T}_{3}\right)$, and further normalized to the PA3TK-luc control as well as $\beta$-galactosidase activity ( $T_{3}$-induced changes were normalized to that of $\beta$-gal). Columns, mean values obtained from at least three independent experiments performed in triplicate; bars, SE. (F) ChIP assay demonstrating that TR is recruited to the BSSP4 5'-flanking region, together with RXR in HepG2-TRa1 and J7-TRa1 cells. Two sets of primers for BSSP4 TRE, positive control TRE (FURIN) and negative control (GAPDH) were prepared.

view of several earlier findings that proteases function in extracellular matrix remodeling during cancer cell progression and development [10], we aimed to ascertain whether BSSP4 also plays a role in cancer processes.

The proliferation rates of the two stably overexpressing BSSP4 cell lines (Huh7-BSSP4 \#1 and \#2) were similar to those of the two control cell lines (Huh7-control \#1 and \#2), as shown in Additional file 3: Figure S3A.
However, cell lines overexpressing BSSP4 displayed significantly increased ( $\sim 3$ to 6 -fold) migration (Figure $2 \mathrm{~B}$ ) and invasion (Figure $2 \mathrm{C}$ ), compared with control cells. Our results indicate that BSSP4 functions in cell migration and invasion, but has no effect on cell growth. Furthermore, after depleted BSSP4 in Mahlavu cells, the migration ability of Mahlavu-BSSP4-depleted cells was decreased compared with Mahlavu-control cells by the Transwell assay
A

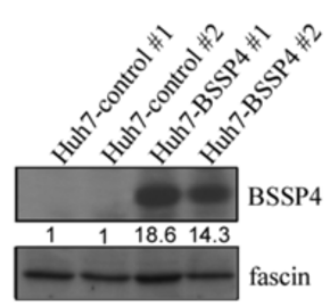

B

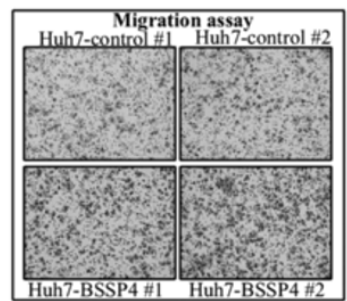

C

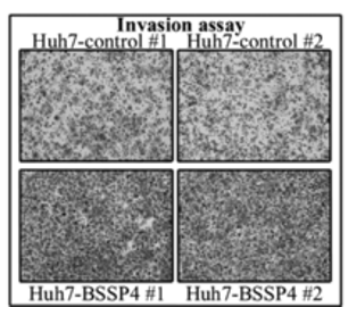

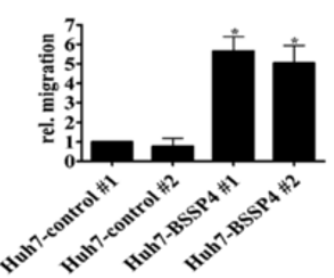

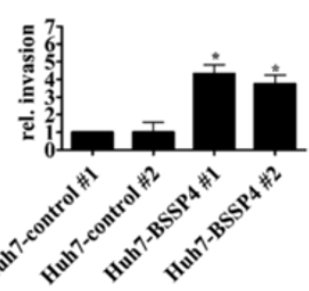

D

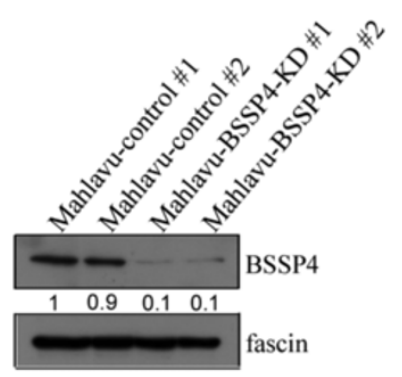

E
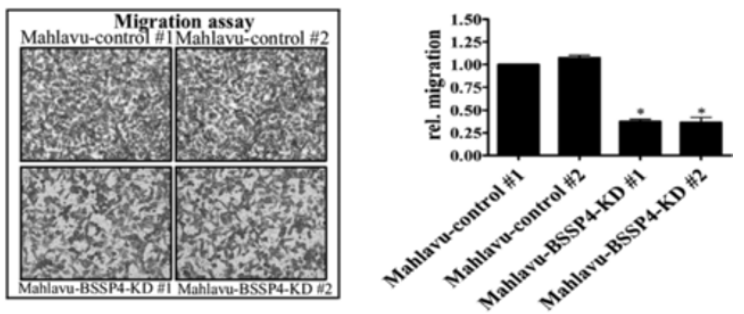

Figure 2 BSSP4 promotes cell motility in vitro. Expression of BSSP4 was detected in BSSP4-overexpressing clones (\#1, \#2) and controls (control \#1, \#2) with Western blotting (A). (B) Migration and (C) invasion abilities were analyzed in two BSSP4 overexpressing and two control cell lines using a Transwell assay. The number of cells traversing the filter to the lower chamber was expressed as the total number of cells to provide an index of migration and invasion activity. Transwell filters were stained with crystal violet in the left panel, and migration and invasion abilities quantified in the right panel. (D) Expression of BSSP4 in Mahlavu-control cells (\#1, \#2) and Mahlavu-BSSP4-KD cells (\#1, \#2) was determined by Western blotting. The migration ability was also examined with a Transwell assay (E). 
(Figure 2D, E). Based on the functional assay in BSSP4depleted and BSSP4-overexpressed cells, BSSP4 has the ability to accelerate tumor cell migration.

\section{BSSP4 influences EMT progression markers}

To further clarify the mechanisms involved in BSSP4regulated cell migration and invasion, we selected several markers of epithelial-mesenchymal transition (EMT) for examination [11]. Figure 3A presents BSSP4 expression levels in Huh7-BSSP4 and Huh7-control cells. The Ncadherin level was increased and E-cadherin decreased in BSSP4-overexpressing cells (Huh7-BSSP4 \#1 and \#2), compared with control cells (Huh7-control \#1 and \#2), on a Western blot (Figure 3B). Based on these results, we propose that the EMT process is involved in BSSP4mediated cancer cell progression.

\section{BSSP4 and $\mathrm{T}_{3}$ regulate cancer-related molecules}

Previously, Yasuda et al. [6] demonstrated that BSSP4 is a serine protease that catalyzes the progression of zymogen pro-uPA to form active uPA. Moreover, the uPA-uPAR system has been linked to the mitogen-activated protein kinase (MAPK)/extracellular signal-regulated kinase (ERK) signaling pathway [12-14]. ERK kinases are frequently abnormally activated in most human cancers, leading to proliferation and acceleration of other oncogenic processes, such as angiogenesis and survival [15]. Accordingly, we examined whether the ERK pathway is implicated in
BSSP4-induced phenotypes. Our results showed marked upregulation of phosphate-ERK in BSSP4-overexpressing cells (Huh7-BSSP4 \#1 and \#2), compared with control cells (Huh7-control \#1 and \#2) (Figure 3C). A number of groups have identified CCAAT/enhancer-binding protein beta $(\mathrm{C} / \mathrm{EBP} \beta$ and vascular endothelial growth factor (VEGF) as ERK downstream genes [16]. VEGF facilitates the formation of new vessels in angiogenesis and plays a critical role in tumor metastasis. Its expression is highly correlated with tumor cell metastasis potency in various cancers [17]. Similarly, C/EBP plays diverse roles in multiple cellular processes, such as the cell cycle, extracellular signaling, tissue development, and is implicated in cancer processes [18]. Subsequently, we investigated whether C/ EBP $\beta$ and VEGF are targeted by BSSP4. Notably, C/EBP $\beta$ was upregulated in the nucleus and VEGF was extensively secreted into the medium in BSSP4-expressing cells (Huh7-BSSP4 \#1 and \#2), compared with their control counterparts (Huh7-control \#1 and \#2) (Figure 3C, D).

We further examined whether this BSSP4-mediated mechanism occurs in $\mathrm{T}_{3}$-regulated hepatoma cells. Our results showed upregulation of nuclear phosphate-ERK and C/EBP $\beta$ after $T_{3}$ stimulation in both HepG2-TR $\alpha 1$ and J7TR $\alpha 1$ cells (Figure 3E). Additionally, VEGF secretion into the medium was increased in $\mathrm{T}_{3}$-treated HepG2-TR $\alpha 1$ and J7-TR $\alpha 1$ cells (Figure 3F). Accordingly, we conclude that stimulation of ERK, C/EBP $\beta$ and VEGF expression by $\mathrm{T}_{3}$ in HepG2-TR $\alpha 1$ or J7-TR $\alpha 1$ cells is mediated via BSSP4.

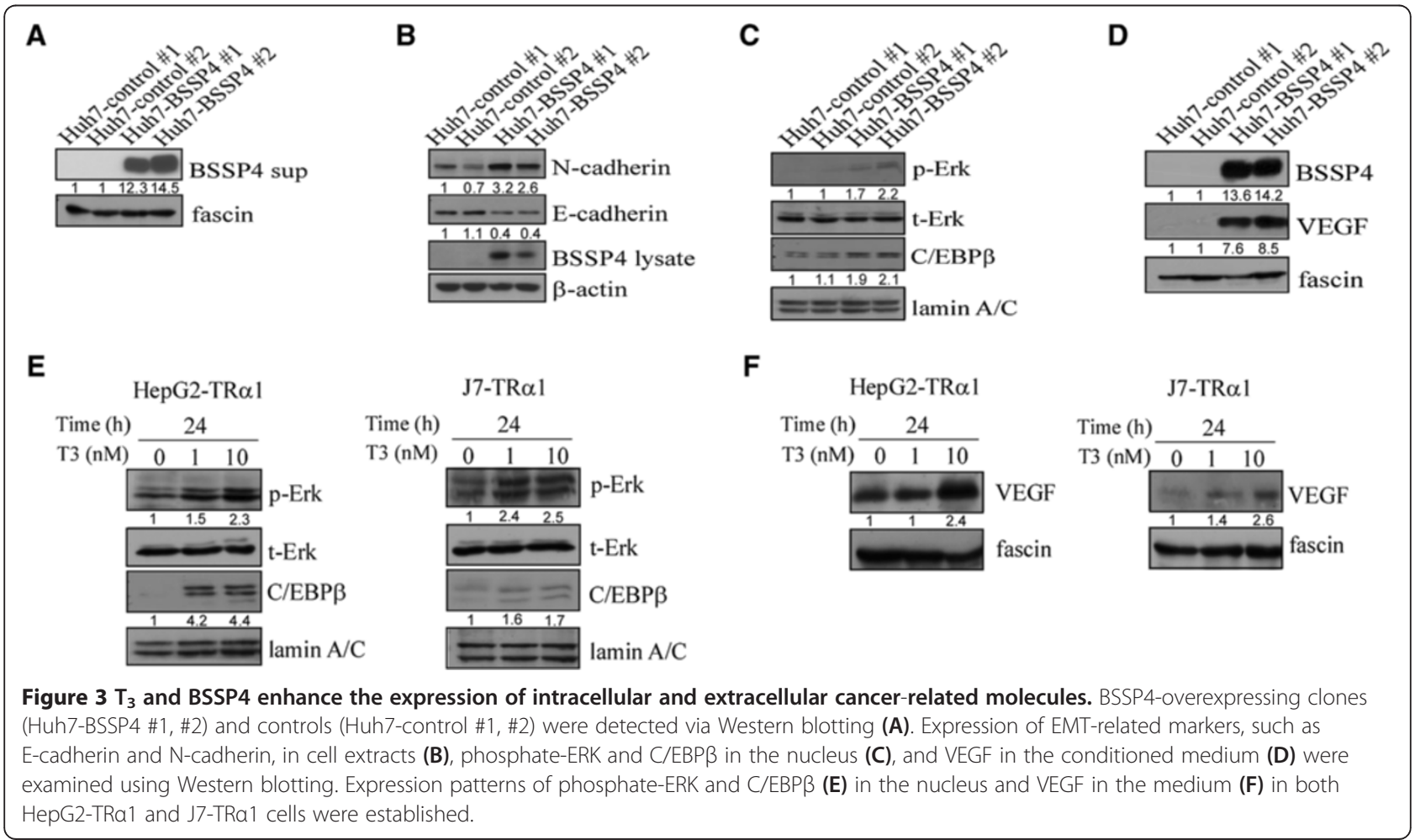




\section{BSSP4 and $\mathrm{T}_{3}$ mediate cell migration via the ERK signaling pathway}

In view of the above results, we hypothesized that $T_{3}$ regulates BSSP4 through the ERK-C/EBP $\beta$-VEGF cascade, leading to cancer cell progression. To examine this possibility, we treated stable Huh7-BSSP4 cell lines with DMSO and U0126, a MEK inhibitor [19,20], followed by the migration and invasion assays. The migration and invasion ability of BSSP4-overexpressing cells (Huh7-BSSP4 \#1 and \#2) was increased about 4-fold, relative to control cells (Huh7-control \#1) (Figure 4A, B). However, this increase was abolished by approximately $25 \%$ upon U0126 treatment of BSSP4-expressing cells (Huh7-BSSP4 \#1 and \#2) (Figure 4A, B). The quantified results are shown in Figure 4A, B, lower panel. Based on these findings, we propose that the ERK pathway is implicated in BSSP4-mediated cell migration. We further ascertained whether this phenomenon occurs in $\mathrm{T}_{3}$-regulated hepatoma cells. As expected, the migration and invasion ability of J7-TR $\alpha 1$ cells was enhanced ( $\sim 3.5$-fold) after $\mathrm{T}_{3}$ stimulation (Figure $4 \mathrm{C}, \mathrm{D})$, which was attenuated $(\sim 30 \%)$ upon U0126 treatment (Figure 4C, D). The quantified results are illustrated in Figure 4C, D, lower panel. Thus, BSSP4 appears to mediate cell migration through the ERK signaling pathway.

\section{The ERK-C/EBP $\beta$-VEGF pathway is involved in BSSP4 and $\mathrm{T}_{3}$-mediated cell migration}

We observed upregulation of $\mathrm{p}-\mathrm{ERK}, \mathrm{C} / \mathrm{EBP} \beta$ and VEGF in both BSSP4-overexpressing and $\mathrm{T}_{3}$-treated hepatoma cells. Moreover, the ERK signaling pathway is clearly involved in BSSP4- and $\mathrm{T}_{3}$-modulated cell migration ability. This led us to investigate whether C/EBP $\beta$ and VEGF are influenced by blocking the ERK signaling pathway. Our results showed that expression levels of nuclear p-ERK and $\mathrm{C} / \mathrm{EBP} \beta$ are decreased in stable Huh7-BSSP4 cells after U0126 treatment, compared with those in control cells (Figure 5A, lanes 7, 8 vs 3,4). VEGF secretion into the medium of stable Huh7-BSSP4 cells was additionally attenuated following U0126 treatment (Figure 5B, lanes 7, 8 vs 3,4$)$. We further determined whether BSSP4 has a similar influence in $\mathrm{T}_{3}$-treated hepatoma cells. Interestingly, in both $\mathrm{T}_{3}$-treated HepG2-TR $\alpha 1$ and J7-TR $\alpha 1$ cells, expression of $\mathrm{p}$-ERK and C/EBP $\beta$ in the nucleus was blocked after U0126 treatment, compared with control cells (Figure 5C, D). Furthermore, VEGF secretion into the medium was significantly attenuated following U0126 treatment in both $\mathrm{T}_{3}$-treated cell lines (Figure 5E, F). Furthermore, the p-VEGFR and VEGFR expression were determined in BSSP4- and TR-overexpressing cells. The p-VEGFR level was increased in BSSP4-overexpressing cells. Consistently, the p-VEGFR expression was upregulated after $T_{3}$ treatment in the HepG2-TR $\alpha$ cell (Additional file 4: Figure S4). A Similar result can be observed in J7-TR $\alpha$ cell (data not shown). Therefore, we speculate that BSSP4 influenced tumor motility may through VEGF-VEGFR cascade.

The relationship between BSSP4 and cancer-related molecules and pathways was investigated using Human Cancer PathwayFinder RT Profiler metastasis-associated PCR Arrays (Quiagen; Kowloon, Hong Kong). We found 20 genes were altered (about $1.5 \sim 3$ fold) in BSSP4 overexpressing cells. The BSSP4-regulated molecules are divided into several categories based on the functions such as cytokines and chemokine pathway (IL-18, CCL7, CXCL12), cell to cell adhesion pathway (PNN, SYK, MCAM), metastasis-related genes (GNRH1, TIMP2, KISS1R, TSHR, TRPM1, SSTR2), transcription factors and regulators (RORB, NR4A3, SMAD2, SMAD4), ECM cleavage pathway (MMP7) and cell cycle regulation (PTEN) were altered (Additional file 5: Figure S5). Thus, BSSP4 may play a role in cancer progression via alteration of related genes. Our results collectively indicate that BSSP4 is upregulated by $\mathrm{T}_{3}$, and subsequently activates the ERK-C/EBP $\beta$-VEGF cascade to promote cancer cell progression.

\section{BSSP4 is associated with cell motility in vitro and in vivo}

To verify whether the in vitro effect of BSSP4 also occurs in vivo, SCID mice were injected with Huh7-BSSP4 and Huh7-control cells. However, no tumors were observed in the lung and liver in either cell line. Based on these findings, we speculated that the Huh7 hepatoma cell line is non-tumorigenic. Therefore, a stable J7BSSP4 cell line was established. Notably, the BSSP4 level was increased in two stably expressing BSSP4 clones (J7-BSSP4 \#1 and \#2), compared to two control cell lines (J7-control \#1 and \#2) (Figure 6A). Similar to Huh-7 cells, proliferation was not influenced in stable BSSP4-overexpressing J7 cell lines, compared with controls (Additional file 3: Figure S3B). Moreover, BSSP4overexpressing cells (J7-BSSP4 \#1 and \#2) showed higher migration and invasion abilities, relative to their control cell counterparts (J7-control \#1 and \#2, respectively) (Figure 6B, C). The in vitro phenotypes were similar between Huh7-BSSP4 and J7-BSSP4 cell lines (Figures 2 and 6). Additionally, we have established J7-TR-BSSP4 knockdown (KD) cell lines. The BSSP4 expression in control cells was induced by $\mathrm{T}_{3}$, however, the induction was abolished in the J7-TR-BSSP4 KD cells (Figure 6D, E). Obviously, the migration ability of J7-TR-control cells was enhanced by $\mathrm{T}_{3}$ stimulation, however, the effect was attenuated in the J7-TR-BSSP4 KD cells (Figure 6E) restoring a more "normal" phenotype. The migration ability was significantly $(p<0.018)$ restored in J7-TR-BSSP4-KD-T 3 cell line after T3 treatment compared to the BSSP4 silencing J7-TR-BSSP4-KD cell line (Figure 6E, right panel). Based on the evidences, the migration phenotype in 


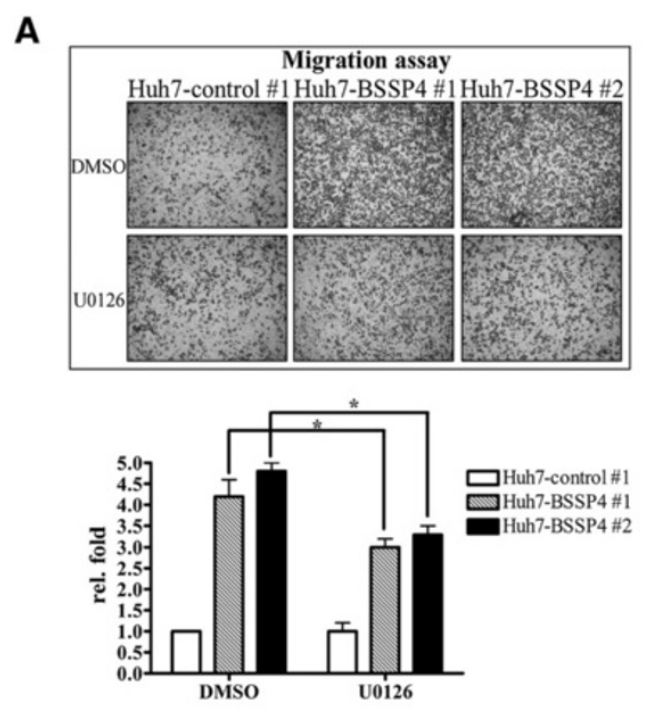

B
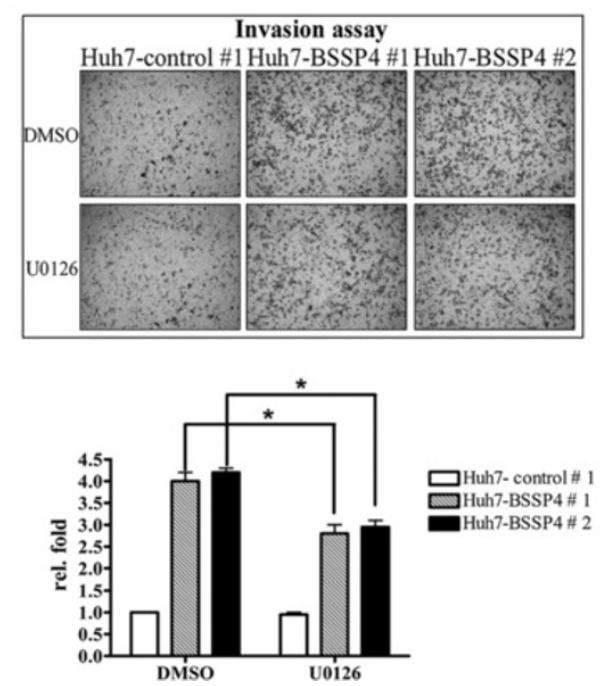

C
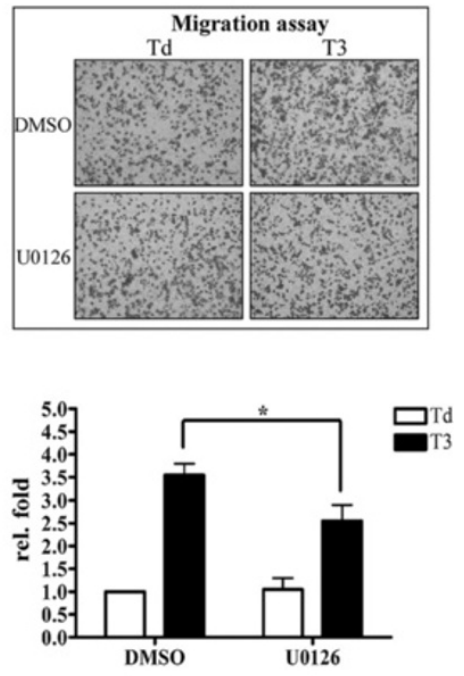

D
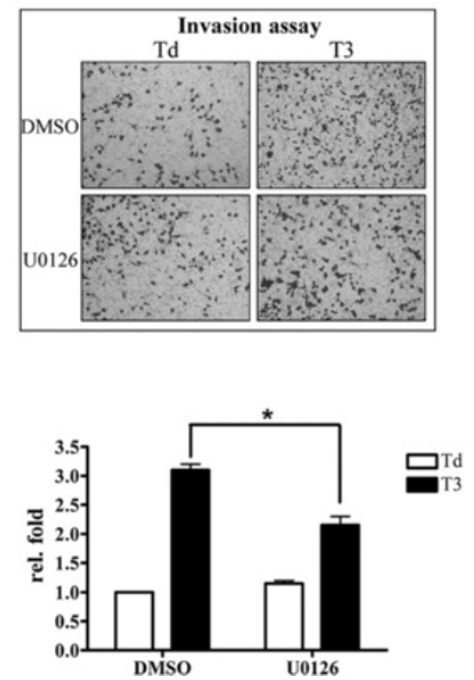

Figure 4 BSSP4- and $\mathrm{T}_{3}$-mediated cell migration occurs via the ERK signaling pathway. The transwell migration (A, C) and invasion assays (B, D) were performed for two BSSP4-expressing (Huh7-BSSP4 \#1, 2) and one control (Huh7-BSSP4 \#1) cell line (A, B), and J7-TRa1 cells (C, D). Stable lines $\left(10^{5}\right) \mathbf{( A , B}$ and $\mathrm{T}_{3}$-treated J7-TRa1 $\left(5 \times 10^{4}\right) \mathbf{( C ,}$ D) cells were treated with DMSO and U0126 $(10 \mu \mathrm{M})$ added to the upper chamber of Transwell units, followed by incubation for $24 \mathrm{~h}$. Transwell filters were stained with crystal violet in the upper panel, and migration ability quantified in the lower panel. Values are shown as fold increase of Huh7-BSSP4 relative to Huh7-control, and $\mathrm{T}_{3}$ relative to Td. Differences were analyzed using One-way ANOVA, ${ }^{*} P<0.05$.

the $\mathrm{T}_{3}$-treated hepatoma cells can be restored in a BSSP4-KD condition.

SCID mice were employed to examine whether the in vitro effects of J7-BSSP4 can be replicated in vivo. Significantly, in SCID mice, J7-BSSP4 cells formed higher numbers of lung foci (Figure 7A) and had a higher metastatic index (Figure 7B), compared with control cells, as well as elevated BSSP4 expression, as evident from $\mathrm{H} \& \mathrm{E}$ staining (Figure $7 \mathrm{C}, \mathrm{D}$, upper panel) and $\mathrm{IHC}$ (Figure $7 \mathrm{C}, \mathrm{D}$, lower panel) analyses, respectively. Based on these findings, we conclude that BSSP4 promotes cell migration and invasion in $\mathrm{J} 7$ hepatoma cells, both in vitro and in vivo.

\section{BSSP4 is upregulated in human HCC and animal models}

Next, we examined the clinicopathologic significance of BSSP4 expression in HCC and evaluated the correlation between TRs and BSSP4. Overall, 74 consecutive HCC patients were enrolled, and their BSSP4 levels analyzed using Western blot. Among the 74 HCC sample pairs, the BSSP4 was overexpressed in 52.7\% (39 of 74) cancerous tissues, compared with matched noncancerous tissues. 


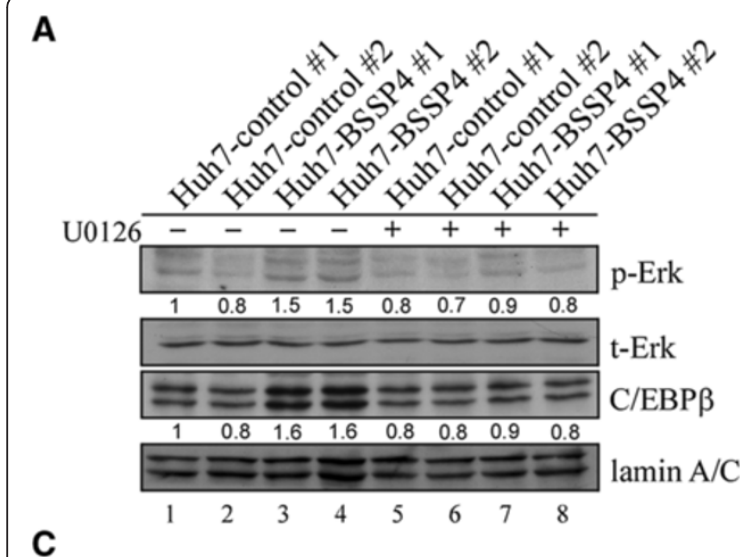

HepG2-TR $\alpha 1$

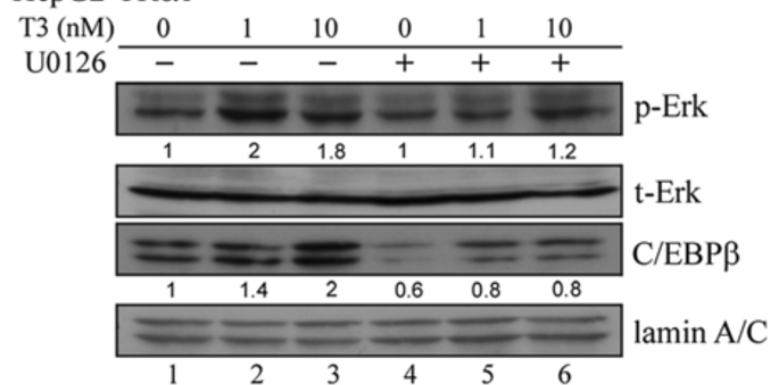

E

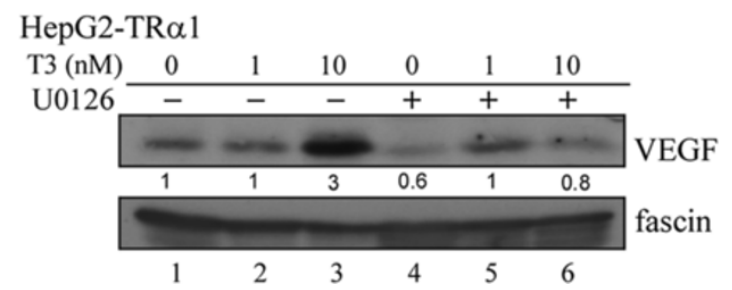

B

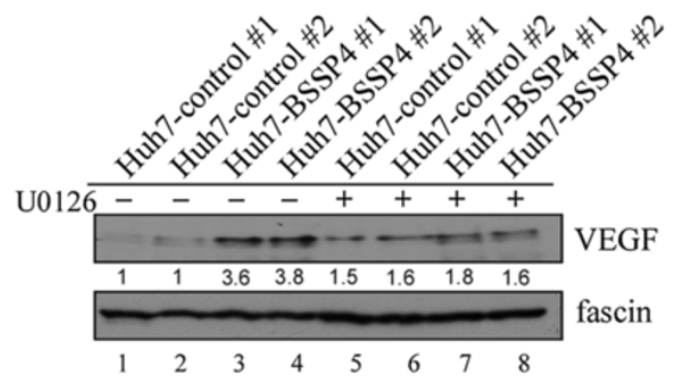

D

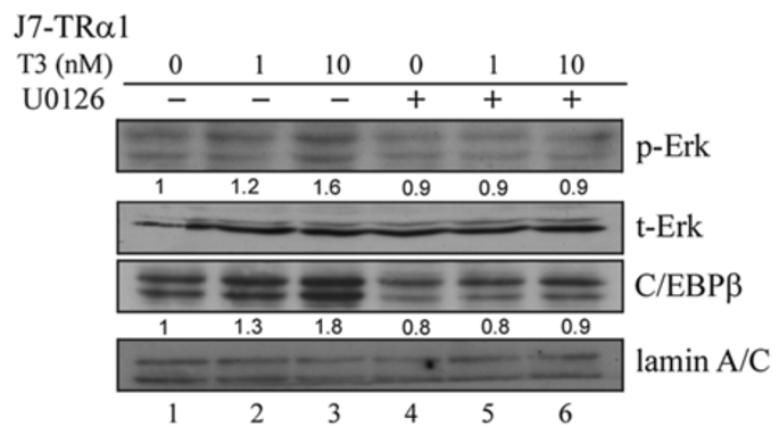

F

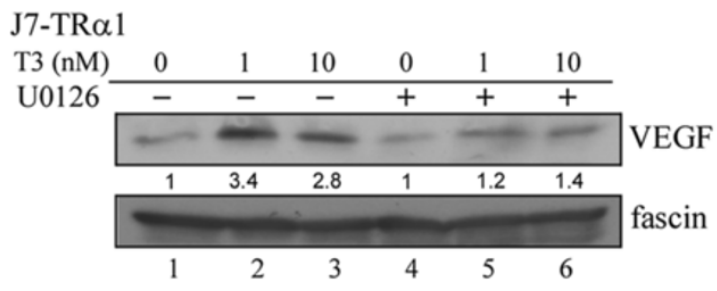

Figure $5 T_{3}$ and BSSP4 promote cell migration via the ERK-C/EBPB-VEGF cascade. We determined the expression patterns of phosphate-ERK and $\mathrm{C} / \mathrm{EBP} \beta$ in the nucleus (A, C, D) and VEGF in conditioned medium (B, E, F) in BSSP4-expressing clones (Huh7-BSSP4 \#1, \#2), controls (Huh7-control \#1, \#2) (A, B), and T-stimulated (0, 1, 10 nM) HepG2-TRa1 (C, E) and J7-TRa1 (D, F) treated with DMSO or U0126 (10 $\mu$ M) using Western blot analysis.

Furthermore, both TR $\alpha 1$ and TR $\beta 1$ levels were elevated by about $29.7 \%$ (22 of 74 ) in cancerous tissues. We have examined the p-ERK in clinical samples (Figure 8A). The p-ERK expression was higher in tumor than the normal counter- parts, and the tendency was the same with BSSP4 expression. Increased BSSP4 expression and concomitantly elevated TR levels in HCC tissues of 12 representative paired $\mathrm{HCC}$ specimens are presented in Figure 8A. The correlation between TRs and BSSP4 was additionally analyzed. Linear regression analysis revealed a significant positive correlation between BSSP4 expression and TR levels, based on the $\mathrm{T} / \mathrm{N}$ ratio (Spearman correlation coefficient $=0.445 ; 95 \%$ confidence interval $(\mathrm{CI})=$ 0.154-0.665; $\mathrm{P}=0.003$ ) (Figure $8 \mathrm{~B}$ ). We have examined the correlation between BSSP4 and several parameters. A mild association between BSSP4 expression and distant metastasis is observed. Patients with $\mathrm{T} / \mathrm{N}<1.5$ are less likely to have distant metastasis $>1$ year than patients with $\mathrm{T} / \mathrm{N}>1.5(\mathrm{P}=0.043)$. BSSP4 and VEGF levels in HCC tissues were determined using the Q-RT-PCR. We observed overexpression of BSSP4 and VEGF in 50\% (26 of 52) and $61.5 \%$ (32 of 52) clinical specimens of HCC, respectively. Additionally, the $\mathrm{T} / \mathrm{N}$ ratios of VEGF and BSSP4 expression revealed a significant positive correlation (Spearman correlation coefficient $=0.504 ; 95 \%$ confidence interval $(C I)=0.260-0.687 ; \mathrm{P}=0.0001$ ) (Figure 8C; Table 1). We have added statistics information in "Additional file 6: Figure S6" to show the correlation in BSSP4 expression 


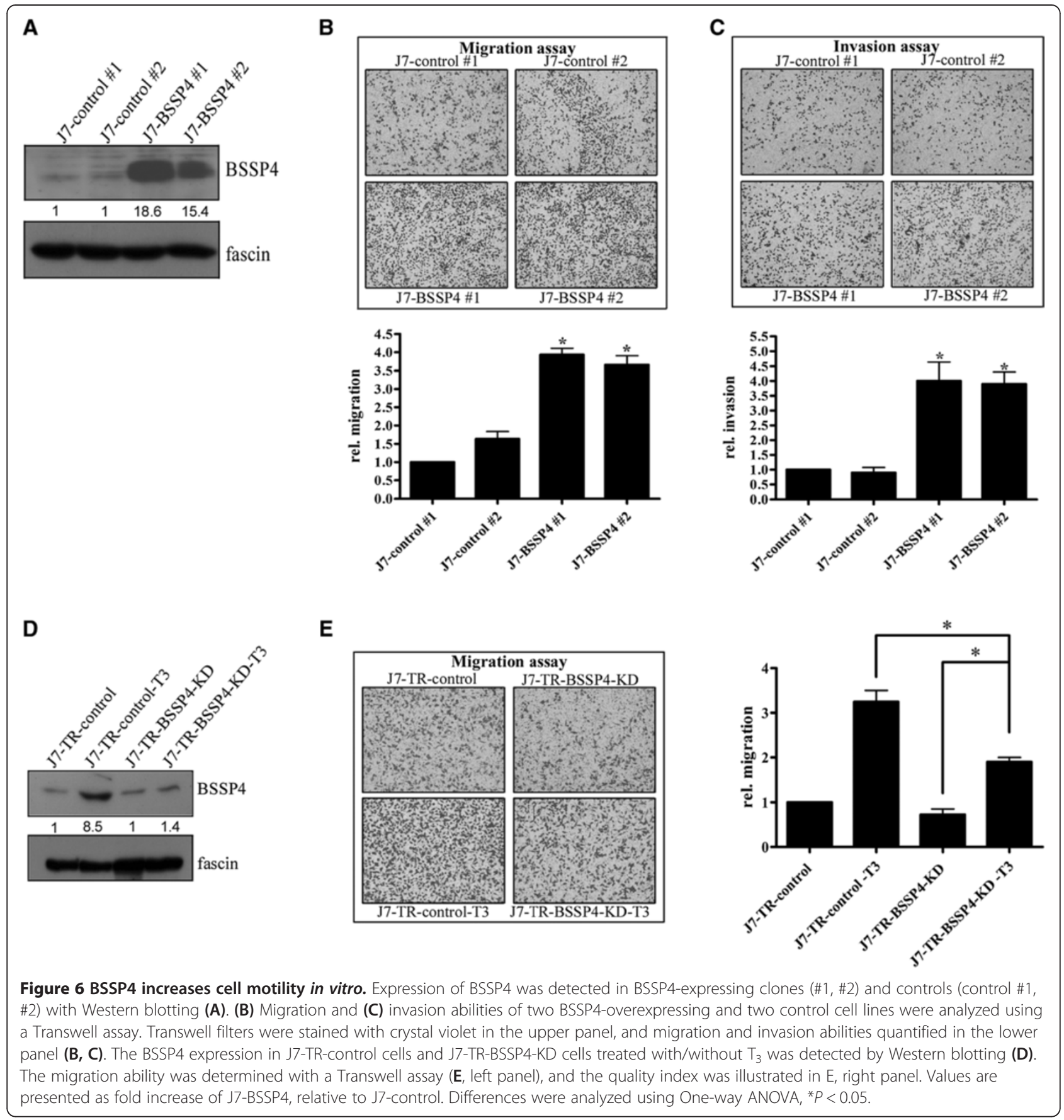

and important parameters in $\mathrm{HCC}$ patients. Among them, bilirubin level was significantly $(P=0.043)$, cirrhosis was marginally $(P=0.057)$ associated with BSSP4 expression. Notably, the expression of BSSP4 between TR $\alpha$ (Additional file 7: Figure S7A, Spearman $r=0.63, P<0.001$ ) and TR $\beta$ (Additional file 7: Figure S7B, Spearman $r=0.6, P<0.001$ ) were demonstrated a significantly positive correlation in public Oncomine microarray data sets. Further, KaplanMeier analysis was used to analyze the correlation of BSSP4 expression with clinical parameters, including tumor size, tumor grade, tumor number, microvascular invasion and macrovascular invasion...etc. (Additional file 8: Figure S8). Based on the data, the overall survival was significantly associated with HBsAg, ascites and tumor number. The HBsAg status was significantly associated with distant metastasis $>1 \mathrm{y}(p<0.001)$. Moreover, the BSSP4 T/N ratio was also significatnly associated with distant metastasis $>1 \mathrm{y}(p=0.043)$. The significantly associated 


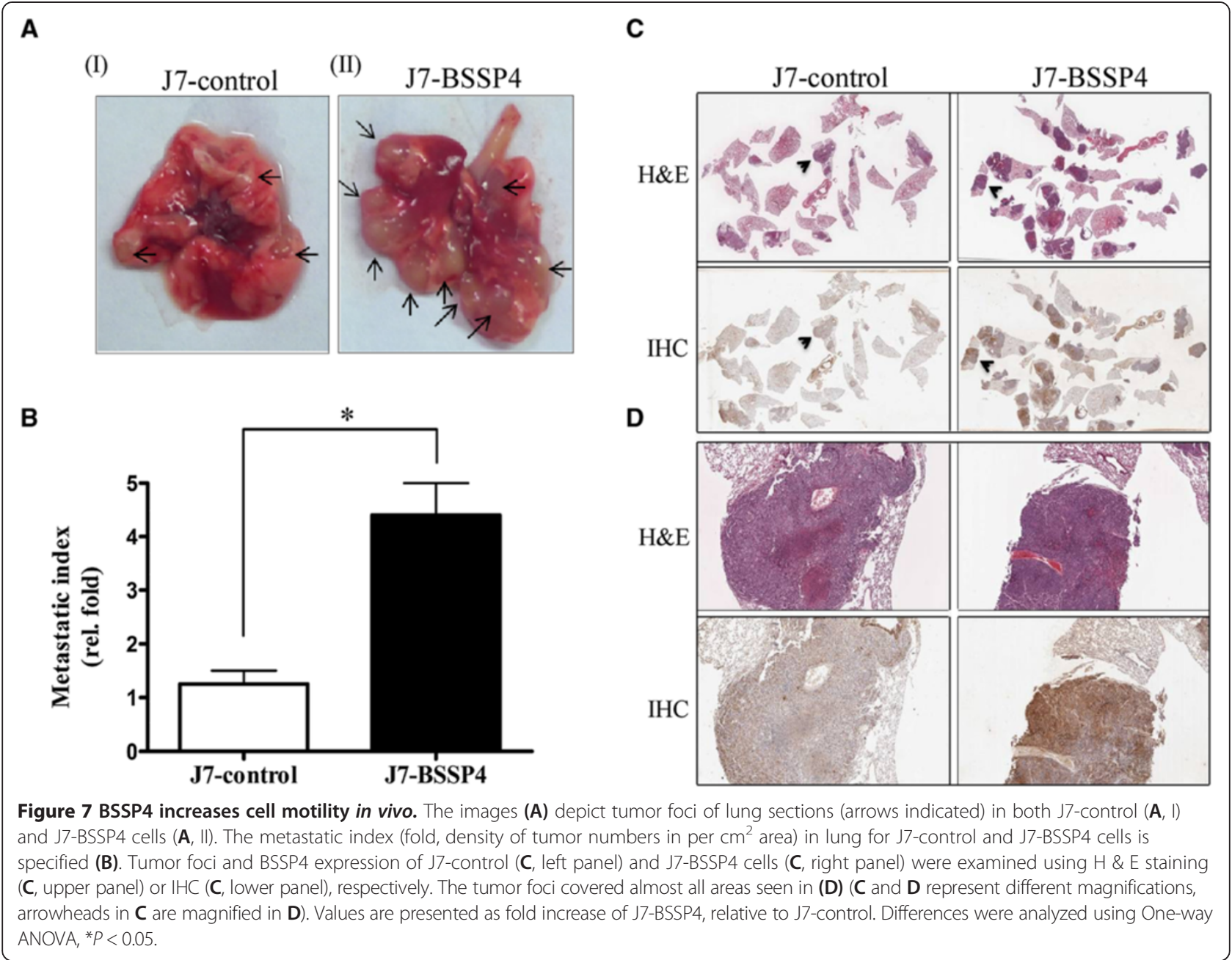

parameters were shown in bold letters in the Additional file 8: Figure S8. Finally, the significant $(p<0.01)$ correlation between TR and BSSP4 was found in clinical HCC specimens (Figure 8A, B, C). Thus, the TR and BSSP4 expression levels were positively associated in vitro or in vivo. Both our in vitro and in vivo findings support the use of BSSP4 as an effective therapeutic target for HCC therapy.

To determine the function of BSSP4 induced by $\mathrm{T}_{3}$, J7-TR $\alpha 1$ cells were employed. BSSP4 mRNA and protein expression was regulated in a dose- and time-dependent manner in J7-TR $\alpha 1$ cells (Figure 8D). To further investigate whether the $\mathrm{T}_{3}$-regulated effect in vitro is replicable in vivo, SCID mice were injected with J7-TR $\alpha 1$ cells and treated under several $\mathrm{T}_{3}$ conditions [5]. Mice injected with J7-TR cells displayed multiple macroscopic lung tumor nodules, as determined by hematoxylin and eosin (H \& E) staining. Tumor size was calculated per $\mathrm{cm}^{2}$ of lung section and the metastatic index was significantly greater in hyperthyroid mice than in euthyroid condition.
Higher $\mathrm{T}_{3}$ levels (hyperthyroid conditions) enhanced BSSP4 expression and number of lung foci, as observed with IHC (Figure 8E, upper panel) and $\mathrm{H} \& \mathrm{E}$ staining (Figure 8E, lower panel) [5]. The BSSP4 expression level in metastatic lung section foci of hyperthyroid was obviously higher than euthyroid mice. Moreover, we observed $\mathrm{T}_{3^{-}}$induced cancer cell invasion and BSSP4 expression in vivo, suggesting that $\mathrm{T}_{3}$ influences tumor motility via BSSP4 regulation.

\section{Discussion}

In a previous stable isotope labeling with amino acids in cell culture (SILAC)-based quantitative proteomics study of a thyroid hormone-regulated secretome in human hepatoma cells, BSSP4 was shown to be upregulated 3.25 -fold by $\mathrm{T}_{3}$ [5]. Here we have shown that BSSP4 is modulated by $\mathrm{T}_{3}$ at both the mRNA and protein levels. Additional studies confirmed that $\mathrm{T}_{3}$ regulates BSSP4 at the transcriptional level, and TR and RXR $\alpha$ complexes directly bind TRE between positions -609 and -594 of the 
A

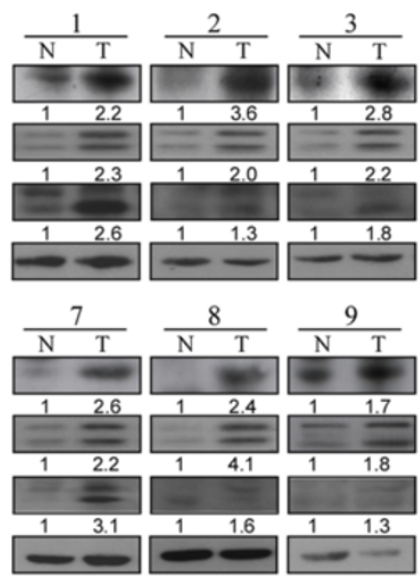

B

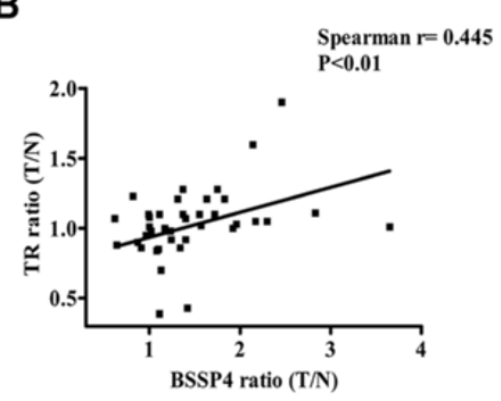

D
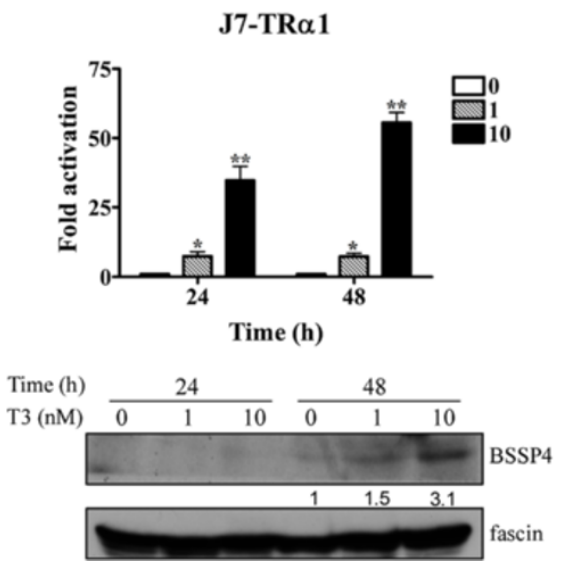
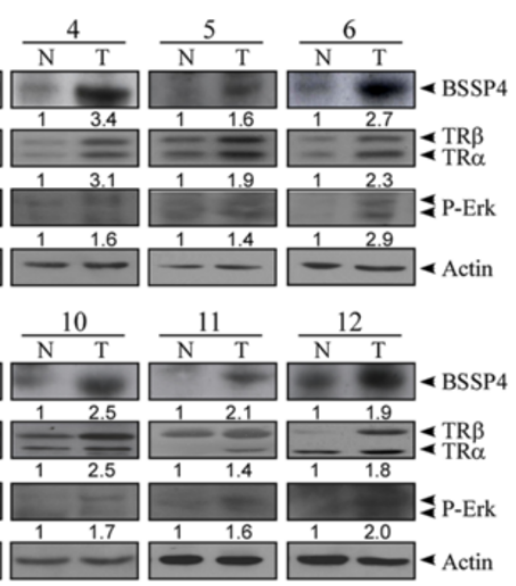

C

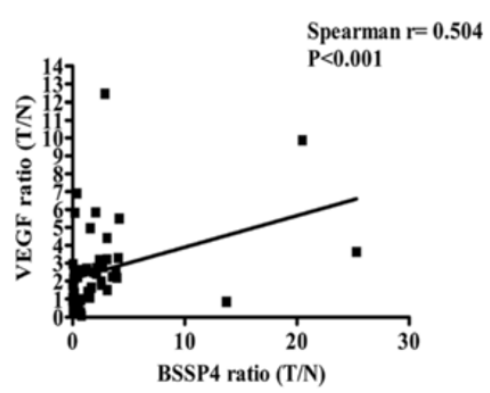

$\mathbf{E}$

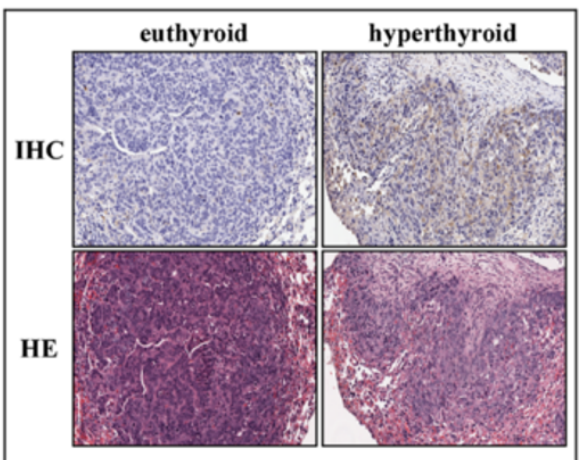

Figure 8 BSSP4 expression is upregulated in vitro and in vivo, and the T/N ratios of BSSP4 and TR levels are positively correlated in HCC. (A) The BSSP4, TRa/TR $\beta$ and P-Erk proteins in HCC specimens were determined using Western blotting. TRs and BSSP4 were overexpressed in 12 representative tumor tissues. The correlations of T/N ratios between BSSP4 and TR (B) and BSSP4 and VEGF (C) were analyzed using linear regression analysis. BSSP4 regulation by $\mathrm{T}_{3}$ at different concentrations $(0,1$ and $10 \mathrm{nM})$ and time-points (24 and $48 \mathrm{~h}$ ) was examined in J7-TRa1 cells at (D) both mRNA (D, upper panel) and protein (D, lower panel) levels using Q-PCR (D, upper panel) and Western blotting (D, lower panel), respectively. (E) Lung sections of SCID mice injected with J7-TRa1 cells treated with hyper-T (hyperthyroid) and administered normal drinking water (euthyroid) were analyzed with $\mathrm{IHC}$ (upper panel) and H \& E (lower panel) staining to examine BSSP4 expression (upper panel) and tumor foci (lower panel).

BSSP4 gene $5^{\prime}$-flanking region. Notably, cell lines overexpressing BSSP4 showed higher migration and invasion abilities, both in vitro and in vivo. Moreover, $\mathrm{T}_{3}$ appears to regulate BSSP4 via the ERK1/2/C/EBP $\beta /$ VEGF cascade, leading to cancer cell progression. The sequential events following BSSP4 activation by $\mathrm{T}_{3}$ in hepatoma cells are illustrated in Figure 9.

BSSP4 was initially identified as a member of the serine protease family [7]. More recently, we identified several $\mathrm{T}_{3}$-modulated proteases, such as matrix metalloproteinases 
(MMPs) and cysteine cathepsins. MMPs are zinc- and calcium-dependent endopeptidases involved in proteolytic processing [21,22]. These proteases participate in cellular processes and intercellular communication during cancer progression and development $[10,23,24]$. Based on these findings, we hypothesized that the BSSP4 protease plays a role in $\mathrm{T}_{3}$-influenced cancer cell progression.

In cancer cell progression, epithelial-mesenchymal transition (EMT) is an important step leading to loss of cell-cell adhesion ability. E-cadherin is a transmembrane protein that participates in rearrangement of the cytoskeleton and cell-cell junctions [25]. E-cadherin overexpression attenuates tumor cell migration and metastasis $[11,26]$. When tumor cells from the epithelium transit to the mesenchymal type, $\mathrm{N}$-cadherin expression is increased, and subsequently, cell conformation is altered. Consequently, migration and invasion abilities are increased after cells acquire N-cadherin expression [27]. Notably, expression of $\mathrm{N}$-cadherin is increased and that of E-cadherin is decreased in BSSP4-overexpressing cells, compared with controls. We propose that BSSP4 accelerates tumor cell migration through the EMT or alterations in N-cadherin and E-cadherin expression.

VEGF is widely distributed in almost all malignant cancers, and considered an important tumor angiogenesis factor. The growth factor influences the vascular permeability of vascular endothelial cells and endothelial cell proliferation and migration in vitro, and generates new blood vessels in vivo. To date, several drugs have been effectively used to target VEGF with the aim of inhibiting tumor growth in a mouse model [28]. Chang et al. [29] reported that VEGF induces angiogenesis by distrusting the balance between proteases and protease inhibitors and causing basement membrane degradation. Highly expressed VEGF and increased microvessel density are correlated with decreased survival, and poor prognosis and progression in cancers [30,31]. Roudnicky et al. [32] demonstrated that VEGF is highly expressed in plasma of bladder cancer, compared with healthy controls, and promotes tumor cell migration via elevated expression of endothelial cell-specific molecule 1 (endocan). Yen et al. [33] reported that $\mathrm{HBx}$ induces cell proliferation and VEGF expression by upregulating the mTOR signaling pathway via IKK in HCC. BSSP4 and $\mathrm{T}_{3}$ enhanced VEGF

\begin{tabular}{|c|c|c|c|}
\hline Target expression & TR & BSSP4 & VEGF \\
\hline Low & 6 & 18 & 7 \\
\hline Median & 11 & 8 & 13 \\
\hline High & 35 & 26 & 32 \\
\hline
\end{tabular}

The expression levels (T/N) of TR, BSSP4 and VEGF were determined by QRT-PCR in HCC mRNA level (52 cases). secretion in the medium in both BSSP4-overexpressing and hepatoma cells in our experiments. Accordingly, we speculate that BSSP4 modulates cell motility through regulation of VEGF in the medium.

$\mathrm{C} / \mathrm{EBP} \beta$ is a transcription factor that regulates several target genes implicated in various processes, including cellular proliferation, migration, survival, metabolism and inflammation, and has diverse functions in several cancers [34]. Previously, Sebastian et al. [35] proposed that Rasinduced cell cycle arrest and tumor suppression occur via the ERK1/2 and C/EBP $\beta$ signaling pathways. Therefore, $\mathrm{C} / \mathrm{EBP} \beta$ may be effective as an activator of transcription factors and signal transducers, and modulate various target genes in response to hormone treatment [36]. Additionally, some groups have proposed that $\mathrm{C} / \mathrm{EBP} \beta$ is an effective regulator of oncogene-induced inflammatory secretome [37]. Consistent with earlier reports, we showed that BSSP4 increases C/EBP $\beta$ expression and cell motility through the ERK signaling pathway after U0126 treatment in both stable BSSP4-overexpressing and hepatoma cell lines.

Olazabal et al. [38] proposed that the pituitary hormone, prolactin, induces liver regeneration via activation of transcription factors involved in cell proliferation and liver-specific differentiation and metabolism, such as $\mathrm{C} / \mathrm{EBP}$ and HNF families and the angiogenic and survival factors, VEGF and HIF-1 $\alpha$, after partial hepatectomy. Furthermore, Montano and co-workers reported that VEGF acts as a transcriptional target of HEXIM1, a transcription factor, tumor suppressor and cyclin-dependent kinase inhibitor, via regulation of C/EBP to influence cell invasion and myocardial proliferation and survival [39]. These data are consistent with our report that VEGF functions as an effector of the C/EBP pathway to influence cellular motility and may thus be employed as a downstream target.

Recently, the group of Clarke showed that a novel stroke therapy agent, perlecan domain $\mathrm{V}$, promotes angiogenesis in brain endothelial cells, by inducing expression and secretion of VEGF via phosphorylation of the ERK1/2 pathway [16]. Shen et al. [40] showed that Notoginsenoside Ft1 (Ft1) stimulates angiogenesis by increasing VEGF expression and simultaneously activating the ERK signaling pathway. Feng and colleagues also proposed that lowpower laser irradiation (LPL1) promotes VEGF expression and vascular endothelial cell proliferation via the ERK/Sp1 pathway [41]. In view of the several lines of evidence, including our results, we propose that VEGF may be a downstream signal and regulator mediating cell motility and angiogenesis.

Previously, Yasuda et al. [6] showed that BSSP4 is a protease catalyzing the conversion of pro-uPA to mature uPA, suggestive of a role in the fibrinolysis reaction. The fibrinolysis system is critical in the development of the tumor microenvironment and vascular diseases, such as 


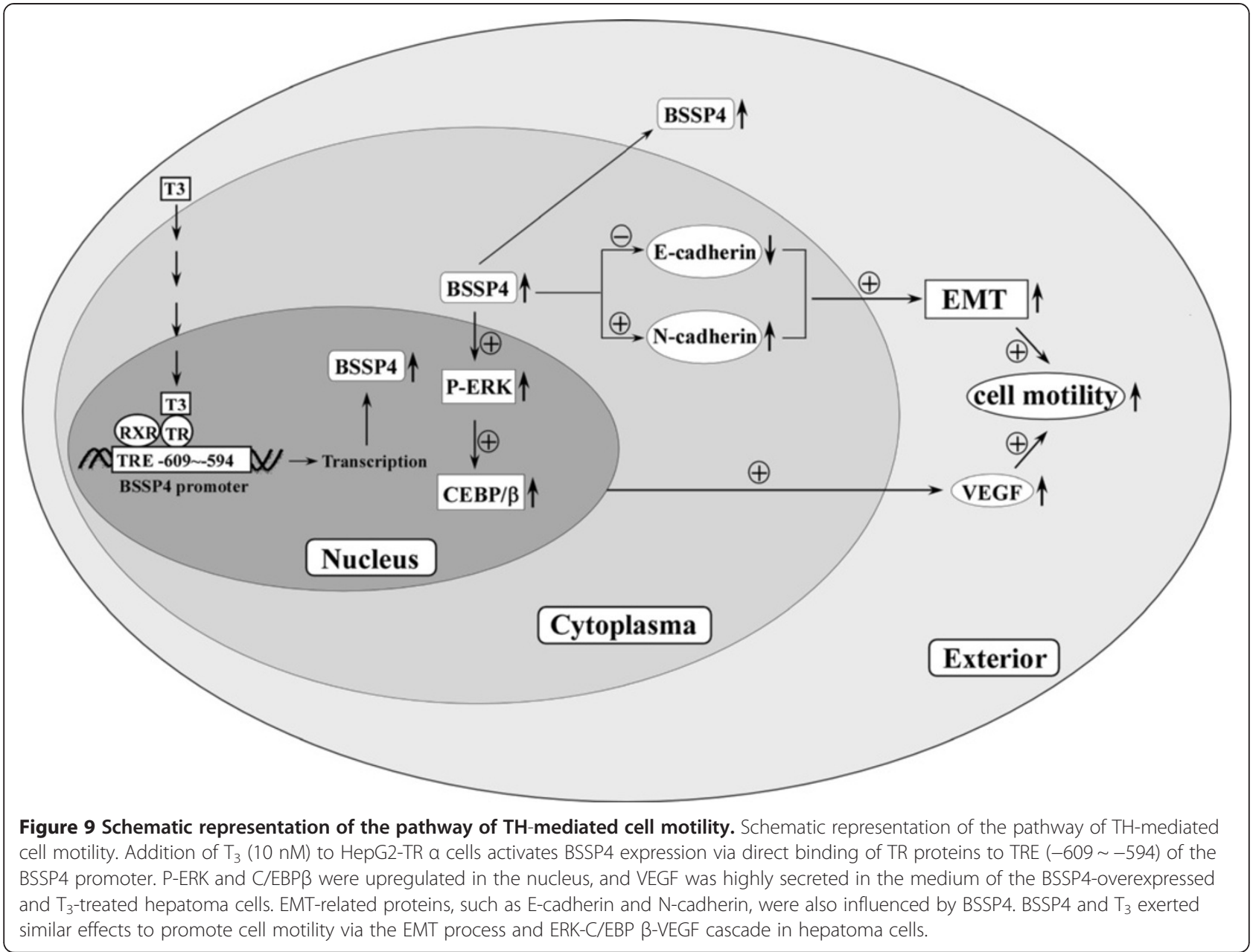

fibrosis, fibrinolysis, thrombosis and atherosclerotic plaques [8]. Furthermore, we propose that the blood coagulation system is mediated by $\mathrm{T}_{3}$, based on MetaCore ${ }^{\mathrm{Tx}}$ software analysis using the SILAC-based quantitative approach [5]. BSSP4 is abundantly found in endothelial cells, leading to the speculation that the protein is preferentially expressed in vascular cells [6]. The uPA system (uPA, tPA, uPAR, PAI-1 and BSSP4) is significantly linked with tumor cell metastasis, which is frequently associated with significant mortality and poor prognosis $[5,8]$. The uPA/uPAR system is highly expressed in almost all human cancers, and associated with short survival and high metastatic potency [8]. Additionally, pro-uPA has been identified as a substrate of BSSP4, which induces enhanced migration ability of prouPA-expressing smooth cells via basement membrane degradation [6]. In our experiments, BSSP4 enhanced migration and invasion abilities in HCC cell lines, both in vitro and in vivo, similar to that observed by other groups. In conclusion, $\mathrm{T}_{3}$-regulated BSSP4 may play a role in vascular endothelial cell motility through activation of VEGF to promote cancer cell progression.

\section{Conclusion}

Our findings collectively support a potential role of $\mathrm{T}_{3}$ in cancer cell progression through regulation of the BSSP4 protease via the ERK 1/2-C/EBP $\beta$-VEGF cascade. BSSP4 was overexpressed in clinical hepatocellular carcinoma (HCC) patients, compared with normal subjects, and positively associated with TR $\alpha 1$ and VEGF to a significant extent. Importantly, a mild association between BSSP4 expression and distant metastasis was observed. BSSP4 may thus be effectively utilized as a novel marker and anti-cancer therapeutic target in HCC.

\section{Materials and methods}

\section{Cell culture}

Human hepatoma cells, HepG2, Huh7 and J7, were routinely cultured at $37^{\circ} \mathrm{C}$ in a humidified atmosphere of 95\% air and 5\% $\mathrm{CO}_{2}$ in Dulbecco's modified Eagle's medium (DMEM) supplemented with 10\% fetal bovine serum (FBS). HepG2 and J7 cell lines were stably transfected with TR $\alpha 1$ (HepG2-TR $\alpha 1 \# 1$, HepG2-TR $\alpha 1 \# 2$ and 
J7-TR $\alpha 1$ ) or TR $\beta 1$ (HepG2-TR $\beta 1)$. The vector control cell line employed was HepG2-neo [42,43]. Huh7-BSSP4 and J7-BSSP4 represent the Huh7 and J7 cell lines expressing BSSP4, respectively. Serum was depleted of $\mathrm{T}_{3}$ (Td), as described previously [44].

\section{Preparation of conditioned medium}

HepG2-TR $\alpha 1 \# 1$, HepG2-TR $\alpha 1 \# 2$, HepG2-TR $\beta 1$, HepG2neo, J7-TR 1 1, Huh7-BSSP4 and J7-BSSP4 cells were grown to confluence in $10 \mathrm{~cm}$ cell culture dishes. Cells contacting dishes were washed twice with PBS, and subsequently incubated in serum-free medium and either treated with $\mathrm{T}_{3}$ for $24 \mathrm{~h}$ or left untreated. At the end of the treatment period, conditioned medium (CM) was collected and concentrated using spin columns with a molecular mass cut-off of $3 \mathrm{kDa}$ (Amicon Ultra, Millipore, Billerica, MA).

\section{Immunoblot analysis}

Total cell lysates and conditioned media were prepared, and protein concentrations determined with the Bradford assay kit (Pierce Biotechnology, Rockford, IL). Equivalent amounts of proteins were fractionated on a $10 \%$ sodium dodecyl sulfate (SDS)-polyacrylamide gel. Separated proteins were transferred on to a nitrocellulose membrane ( $\mathrm{pH}$ 7.9, Amersham Biosciences Inc., Piscataway, NJ), blocked with $5 \%$ non-fat powdered milk, incubated with specific primary antibodies at $4^{\circ} \mathrm{C}$ overnight, and subsequently hybridized with the respective secondary antibody (HRP-conjugated mouse/rabbit/goat anti-IgG) for $1 \mathrm{~h}$ at room temperature. Finally, immune complexes were visualized using the chemiluminescence method with an ECL detection kit (Amersham) on Fuji X-ray film, as described previously [45].

\section{Quantitative reverse transcription polymerase chain reaction (Q-RT-PCR)}

Total RNA was extracted from four $\mathrm{T}_{3}$-treated HepG2 isogenic cell lines using TRIzol reagent, as described previously [46]. Subsequently, cDNA was synthesized via RT-PCR with the Superscript II kit (Life Technologies, Karlsruhe, Germany). Real-time Q-RT-PCR was performed on a $15 \mu \mathrm{l}$ reaction mixture containing $750 \mathrm{nM}$ forward and reverse primers, varying amounts of template and $1 \times$ SYBR Green reaction mix (Applied Biosystems, Foster City, CA). SYBR Green fluorescence was determined using the ABI PRISM 7500 detection system (Applied Biosystems). Primers were designed using Primer Express Software (Applied Biosystems). Genes were normalized against the ribosomal binding protein (RiboL35A) gene. The human BSSP4 oligonucleotides used in this study include the forward primer, 5'-GGTCCCAGAAGGTGGGTGTT -3, and reverse primer, 5' - ACGCACCAGGGCAATGTC -3'.

\section{Cloning and activities of BSSP4 promoter fragments}

Fragments of the BSSP4 promoter (positions -2066 to -7) were ligated into the pA3TK vector (Promega Corp., Madison, WI), based on the published sequence. Several serial deletion and mutant constructs of the BSSP4 promoter were amplified via PCR and cloned into pA3TK. Promoter sequences were confirmed using automated DNA sequencing. HepG2-TR $\alpha 1$ cells treated with $10 \mathrm{nM}$ $\mathrm{T}_{3}$ for $24 \mathrm{~h}$ were cotransfected with $0.6 \mu \mathrm{g}$ DNA/well of pA3TK vector containing the BSSP4 promoter sequence and $0.3 \mu \mathrm{g}$ of SV $\beta$ plasmid, a $\beta$-galactosidase expression vector (Clontech, Palo Alto, CA), in 24-well plates using TurboFect in vitro transfection reagent (Fermentas, Glen Burnie, MD) to determine the transcriptional activities of TREs within the BSSP4 promoter. At the end of the treatment period, transfected and non-transfected cells were lysed, and luciferase and $\beta$-galactosidase activities measured. Luciferase activity was normalized to that of $\beta$ galactosidase, as described earlier [47].

\section{Chromatin immunoprecipitation (ChIP) assay}

ChIP assays were performed to examine the interactions between TR and TRE on the BSSP4 promoter [45]. HepG2-TR $\alpha 1$ cells treated with $10 \mathrm{nM} \mathrm{T}_{3}$ for $24 \mathrm{~h}$ or left untreated were harvested and cross-linked with $1 \%$ formaldehyde for $10 \mathrm{~min}$ at room temperature in DMEM medium. Reactions were terminated by adding $0.125 \mathrm{M}$ glycine. Subsequently, cell lysates were washed three times with PBS, and resuspended in lysis buffer $(150 \mathrm{mM}$ $\mathrm{NaCl}, 5 \mathrm{mM}$ EDTA, $50 \mathrm{mM}$ Tris (pH 8.0), 0.1\% SDS and $0.1 \%$ sodium deoxycholate) containing three protease inhibitors (1 mM PMSF, aprotinin, and leupeptin). Cell lysates were sonicated with a Misonix Sonicator 3000 Homogenizer (Mandel Scientific Company Inc., Guelph, ON, Canada) to disrupt chromatin. Sonicated DNA was between 200 and $1000 \mathrm{bp}$ in length. Products were precleared with $60 \mu \mathrm{l}$ protein A/G agarose (Sigma Chemicals, St. Louis, MO) for $2 \mathrm{~h}$ at $4^{\circ} \mathrm{C}$. Complexes were immunoprecipitated with anti-TR (kindly provided by the laboratory of Dr. S-Y Cheng at the National Cancer Institute), anti-RXR $\alpha$ (Santa Cruz Biotechnology, Santa Cruz, CA) and anti-IgG antibodies ( $R$ \& D Systems, Inc., Minneapolis, MN). The $100 \mathrm{bp}$ fragment of the BSSP4 promoter containing the predicted TRE region was amplified via PCR with the forward primer, 5 ' - CTCCAGGAACGACA GGAGGGCG - 3', and reverse primer, 5'-GCCTGGGT TTGGAGAGGCTGAAGTC- 3'.

\section{Proliferation assay}

Cells $\left(4 \times 10^{4}\right)$ were seeded on a $6 \mathrm{~cm}$ dish and harvested at 1-7 days. The total number of cells in each condition provided a cell growth index via cell counting. Values are presented as fold increase in Huh7-BSSP4 and J7- 
BSSP4, relative to Huh7 and J7 control cells. Differences were analyzed using one-way ANOVA.

\section{Cloning of BSSP4}

Total RNA $(1 \mu \mathrm{g})$ was reverse-transcribed using Superscript II reverse transcriptase (Invitrogen) and Oligo (dT) to synthesize template cDNA. BSSP4 cDNA was amplified via PCR with the forward primer, 5S - CCAAGCTTA TGGTGGTTTCTGGAGCGCCC-3', and reverse primer, 5' - CCGGAATTCCTAGGAGCGCGCGGCGG -3', for 30 cycles at $95^{\circ} \mathrm{C}$ for $1 \mathrm{~min}, 60^{\circ} \mathrm{C}$ for $1 \mathrm{~min}$ and $72^{\circ} \mathrm{C}$ for $2 \mathrm{~min}$. The BSSP4 open reading frame was ligated into pcDNA 3.0 expression vector, and the resulting construct sequenced to confirm the presence of the gene.

\section{Establishing Huh7 and J7 cell lines stably overexpressing BSSP4}

The Huh7 cell line was transfected with the BSSP4 cDNA construct in $10 \mathrm{~cm}$ cell culture dishes using Lipofectamine Reagent (Invitrogen). After $24 \mathrm{~h}$, transfected cells were transferred to medium containing G418 $(400 \mu \mathrm{g} / \mathrm{ml})$ for selection until the generation of a single cell clone. Expression of BSSP4 in Huh7 and J7 cells was detected using Western blotting.

\section{Effect of knocked-down BSSP4 expression}

Short hairpin RNA clones targeting BSSP4 were purchased from the National RNAi Core Facility (Institute of Molecular Biology, Academia Sinica, Taiwan). Transfection of shRNA to against the endogenous BSSP4 gene in Mahlavu and J7-TR cells was transit performed using the Turbofect reagent (Invitrogen). The repression of the BSSP4 was confirmed by western blot analysis.

\section{In vitro migration and invasion assays}

The influence of BSSP4 on migration and invasion abilities of Huh7-BSSP4 and J7-BSSP4 cells was determined with a rapid in vitro assay (Transwell) (Falcon BD, Franklin Lakes, New Jersey), as described previously [48]. Briefly, cell density was adjusted to $10^{5}$ cells $/ \mathrm{ml}$, and $100 \mu \mathrm{l}$ of the suspension seeded on either non-matrigel-coated (migration) or matrigel-coated (invasion) (Becton-Dickinson) upper chambers of the Transwell plate. For both assays, the pore size of the upper chamber was $8 \mathrm{~mm}$. The medium in the upper chamber was serum-free DMEM, while the lower chamber contained DMEM supplemented with $20 \%$ fetal bovine serum (FBS). After incubation for $24 \mathrm{~h}$ at $37^{\circ} \mathrm{C}$, cells traversing the filter from the upper to lower chamber were examined via crystal violet staining and cell counting. Experiments were performed at least three times.

\section{Immunohistochemistry}

Formalin-fixed and paraffin-embedded tissues from the lung of SCID mice were evaluated by hematoxylin and eosin (H \& E) staining and immunohistochemistry using polyclonal antibody against BSSP4 (GeneTex, Inc, San Antonio, Texas) after the avidin-biotin complex method, as described previously. The positive staining consisted of cancer cells with dark brown of BSSP4 immunoreactivity.

\section{Animals}

Similar conditions were employed with SCID mice containing various $\mathrm{T}_{3}$ levels (Group A to $\mathrm{B}$ ) induced via injection of J7-TR cells [5]. Mice were divided into two groups, specifically, Group A (euthyroid) comprising control mice given normal drinking water, and Group B (hyperthyroid) administered drinking water augmented with $\mathrm{T}_{3}(2 \mathrm{mg} / \mathrm{L})$ (Sigma Chem. Co., St. Louis, MO) after inoculation of tumor cells. Mice were sacrificed after about 1 month injection, livers and lungs were removed for tumor biopsy, and the $\mathrm{T}_{3}$ and TSH levels determined. The $\mathrm{T}_{3}$ and TSH levels in the serum of group A were $45.5 \mathrm{ng} / \mathrm{dl}$ and $0.246 \mathrm{mIU} / \mathrm{ml}$, and in group B were $619 \mathrm{ng} / \mathrm{dl}$ and $0.008 \mathrm{mIU} / \mathrm{ml}$, respectively. Tumor volume was calculated using the following equation: length $x$ height $x$ width. Formalin-fixed and paraffin-embedded tissues from SCID mice were evaluated by hematoxylin and eosin ( $\mathrm{H} \& \mathrm{E})$ staining and immunohistochemistry using polyclonal antibody against BSSP4 (GeneTex). All procedures were performed under sterile conditions in a laminar flow hood. Animal experiments were performed in accordance with United States National Institutes of Health guidelines and Chang-Gung Institutional Animal Care and Use Committee Guide for the Care and Use of Laboratory Animals.

\section{Human HCC specimens}

With informed consent, patients with HCC diagnosed between 2000 and 2003 were selected consecutively for this study. All samples of HCC tissues with paired adjacent normal liver tissues were obtained during surgical resection from the Chang Gung Memorial Hospital medical research center for western blot and Q-RT-PCR analysis. The study protocol was approved by the Medical Ethics and Human Clinical Trial Committee at Chang-Gung Memorial Hospital.

\section{Statistical analysis}

Data are expressed as mean values \pm SEM of at least three experiments. Statistical analysis was performed using the Student's $t$ test and one-way ANOVA analysis. $P<0.05$ was considered statistically significant.

\section{Additional files}

Additional file 1: Figure S1. Effect of TR on $T_{3}$ induction of BSSP4 expression in SK-Hep-1 cell. The TRa and TR $\beta$ expression were depleted with siRNA in SK-Hep1 cell (A). The BSSP4 protein level was examined in 
the conditioned medium of SK-Hep-1 and SK-Hep-1-siTRaß cells treated with 1 or 10nM T3 (24 h and $48 \mathrm{~h}$ ) and analyzing by Western blotting (B).

Additional file 2: Figure S2. Expression of BSSP4 in hepatoma cell lines. The BSSP4, or TRa/TR $\beta$ expression levels were detected in six available hepatoma cells (SK-Hep-1, Mahlavu, Huh7, HepG2, J7 and Hep3B) analyzing by Western blotting.

Additional file 3: Figure S3. Effect of proliferation ability by BSSP4 in hepatoma cell lines. Cell growth rates were determined from 1 to 7 days, and expressed as the total number of cells representing index of proliferation ability. (A) Huh7, (B) J7.

Additional file 4: Figure S4. Regulation of VEGFR by BSSP4 and T3 in hepatoma cells. The $\mathrm{p}$-VEGFR and VEGFR expression were examined in Huh7 BSSP4-overexpressing (A) and T3-treated HepG2-TRa1 (B) Cells by Western blotting.

Additional file 5: Figure S5. Pathways or molecules regulated by BSSP4 in hepatoma cells. Several categories based on the functions such as (A) cytokines and chemokine pathway (IL-18, CCL7, CXCL12), (B) cell to cell adhesion pathway (PNN, SYK, MCAM), (C) metastasis-related genes (GNRH1, TIMP2, KISS1R, TSHR, TRPM1, SSTR2) (D) Transcription factors and regulators (RORB, NR4A3, SMAD2, SMAD4) (E) ECM cleavage pathway (MMP7) and (F) cell cycle regulation (PTEN) were determined by metastasis-associated PCR array in Huh7 BSSP4-overexpressing stable cells.

Additional file 6: Figure S6. Clinicopathological correlation of BSSP4 expression and several parameters in hepatoma patients.

Additional file 7: Figure S7. Positive correlation of BSSP4 and TRa/TR $\beta$ expression levels. The correlation between BSSP4 and TRa (A) and TR $(B)$ were analyzed from Oncomine microarray data sets [1].

Additional file 8: Figure S8. Clinicopathological correlation of BSSP4 expression and overall survival rate in hepatoma patients.

\section{Abbreviation}

BSSP4: Brain-specific serine protease 4; C/EBP $\beta$ : CCAAT/enhancer-binding protein $\beta$; ERK: Extracellular signal-regulated kinase; HCC: Hepatocellular carcinoma; MAPK: Mitogen-activated protein kinase; TH: Thyroid hormone; TREs: Thyroid hormone response elements; uPA: urokinase-type plasminogen activator; VEGF: Vascular endothelial growth factor.

\section{Competing interest}

The authors declare that they have no competing interests.

\section{Authors' contribution}

Conception and design: C.Y. Chen, I. H Chung, Y.H. Lin, H.C. Chi, K.H. Lin Development of methodology: Y.H. Lin, C.Y. Chen, M. M. Tsai, K.H. Lin Acquisition of data (provided animals, acquired and managed patients, provided facilities, etc.): C.Y. Chen, I. H Chung, Y. C. Wang, Y.H. Tseng. Analysis and interpretation of data (e.g., statistical analysis, biostatistics, computational analysis): C.Y. Chen, I. H Chung, Y.H. Tseng, C.Y. Tsai, C.P. Chen, T. I. Wu, C. T. Yeh, D. I. Tai, K.H. Lin. Writing, review, and/or revision of the manuscript: C.Y. Chen, I. H Chung, K.H. Lin Administrative, technical, or material support (i.e., reporting or orga-nizing data, constructing databases): C.Y. Tsai, H.C. Chi, K.H. Lin Study supervision: C.Y. Chen, I. H Chung, K.H. Lin. All authors read and approved the final manuscript.

\section{Acknowledgement}

This work was supported by grants from Chang Gung Molecular Medicine Research Center, Taoyuan, Taiwan (CMRPD 170091-93, NMRP 140513, 170651-53) and from the National Science Council of the Republic of China (NSC 96-2320-B-182-007, 97-2320-B-182-025-MY3).

\section{Author details}

'Department of Biochemistry, School of Medicine, Chang-Gung University, 259 Wen-hwa 1 Road, Taoyuan, Taiwan. ${ }^{2}$ Department of Medical Research, Mackay Memorial Hospital, 251 Taipei, Taiwan. ${ }^{3}$ Department of Nursing, Chang-Gung University of Science and Technology, 333 Taoyuan, Taiwan. ${ }^{4}$ Medical Research Central, Chang Gung Memorial Hospital, 333 Taoyuan, Taiwan. ${ }^{5}$ Division of High Risk Pregnancy, Mackay Memorial Hospital, 104 Taipei, Taiwan
Received: 17 December 2013 Accepted: 19 June 2014

Published: 1 July 2014

\section{References}

1. Kim WG, Cheng SY: Thyroid hormone receptors and cancer. Biochim Biophys Acta 2013, 1830:3928-3936.

2. Chen CY, Tsai MM, Chi HC, Lin KH: Biological significance of a thyroid hormone-regulated secretome. Biochim Biophys Acta 2013 1834:2271-2284

3. Huang YH, Tsai MM, Lin KH: Thyroid hormone dependent regulation of target genes and their physiological significance. Chang Gung Med J 2008, 31:325-334.

4. Wu SM, Cheng WL, Lin CD, Lin KH: Thyroid hormone actions in liver cancer. Cell Mol Life Sci 2013, 70:1915-1936.

5. Chen CY, Chi LM, Chi HC, Tsai MM, Tsai CY, Tseng YH, Lin YH, Chen WJ, Huang $\mathrm{YH}$, Lin $\mathrm{KH}$ : Stable isotope labeling with amino acids in cell culture (SILAC)-based quantitative proteomics study of a thyroid hormone-regulated secretome in human hepatoma cells. Mol Cell Proteomics 2012, 11:M111. 011270

6. Yasuda S, Morokawa N, Wong GW, Rossi A, Madhusudhan MS, Sali A, Askew YS, Adachi R, Silverman GA, Krilis SA, Stevens RL: Urokinase-type plasminogen activator is a preferred substrate of the human epithelium serine protease tryptase epsilon/PRSS22. Blood 2005, 105:3893-3901.

7. Wong GW, Yasuda S, Madhusudhan MS, Li L, Yang Y, Krilis SA, Sali A Stevens RL: Human tryptase epsilon (PRSS22), a new member of the chromosome 16p13.3 family of human serine proteases expressed in airway epithelial cells. J Bio/ Chem 2001, 276:49169-49182.

8. Dass K, Ahmad A, Azmi AS, Sarkar SH, Sarkar FH: Evolving role of uPA/uPAR system in human cancers. Cancer Treat Rev 2008, 34:122-136.

9. Mitsui S, Okui A, Kominami K, Konishi E, Uemura H, Yamaguchi N: A novel serine protease highly expressed in the pancreas is expressed in various kinds of cancer cells. FEBS J 2005, 272:4911-4923.

10. Hofmann UB, Eggert AA, Blass K, Brocker EB, Becker JC: Expression of matrix metalloproteinases in the microenvironment of spontaneous and experimental melanoma metastases reflects the requirements for tumor formation. Cancer Res 2003, 63:8221-8225

11. Peinado $\mathrm{H}$, Portillo $\mathrm{F}$, Cano A: Transcriptional regulation of cadherins during development and carcinogenesis. Int J Dev Biol 2004, 48:365-375.

12. Lin Z, Crockett DK, Jenson SD, Lim MS, Elenitoba-Johnson KS: Quantitative proteomic and transcriptional analysis of the response to the p38 mitogen-activated protein kinase inhibitor SB203580 in transformed follicular lymphoma cells. Mol Cell Proteomics 2004, 3:820-833.

13. Celis JE, Moreira JM, Cabezon T, Gromov P, Friis E, Rank F, Gromova I: Identification of extracellular and intracellular signaling components of the mammary adipose tissue and its interstitial fluid in high risk breast cancer patients: toward dissecting the molecular circuitry of epithelial-adipocyte stromal cell interactions. Mol Cell Proteomics 2005, 4:492-522.

14. Yoon SY, Lee YJ, Seo JH, Sung HJ, Park KH, Choi IK, Kim SJ, Oh SC, Choi CW, Kim BS, Shin SW, Kim YH, Kim JS: UPAR expression under hypoxic conditions depends on iNOS modulated ERK phosphorylation in the MDA-MB-231 breast carcinoma cell line. Cell Res 2006, 16:75-81.

15. Wei F, Yan J, Tang D: Extracellular signal-regulated kinases modulate DNA damage response - a contributing factor to using MEK inhibitors in cancer therapy. Curr Med Chem 2011, 18:5476-5482.

16. Clarke DN, Al Ahmad A, Lee B, Parham C, Auckland L, Fertala A, Kahle M, Shaw CS, Roberts J, Bix GJ: Perlecan Domain V induces VEGf secretion in brain endothelial cells through integrin alpha5beta1 and ERK-dependent signaling pathways. PLoS One 2012, 7:e45257.

17. Rajcevic U, Petersen K, Knol JC, Loos M, Bougnaud S, Klychnikov O, Li KW, Pham TV, Wang J, Miletic H, Peng Z, Bjerkvig R, Jimenez CR, Niclou SP iTRAQ-based proteomics profiling reveals increased metabolic activity and cellular cross-talk in angiogenic compared with invasive glioblastoma phenotype. Mol Cell Proteomics 2009, 8:2595-2612.

18. Tsukada J, Yoshida Y, Kominato Y, Auron PE: The CCAAT/enhancer (C/EBP) family of basic-leucine zipper (bZIP) transcription factors is a multifaceted highly-regulated system for gene regulation. Cytokine 2011, 54:6-19.

19. Doerig C, Billker O, Pratt D, Endicott J: Protein kinases as targets for antimalarial intervention: Kinomics, structure-based design, transmission-blockade, and targeting host cell enzymes. Biochim Biophys Acta 2005, 1754:132-150 
20. Tong C, Fan HY, Chen DY, Song XF, Schatten H, Sun QY: Effects of MEK inhibitor U0126 on meiotic progression in mouse oocytes: microtuble organization, asymmetric division and metaphase II arrest. Cell Res 2003 13:375-383.

21. Gomis-Ruth FX: Structural aspects of the metzincin clan of metalloendopeptidases. Mol Biotechnol 2003, 24:157-202.

22. Uria JA, Werb Z: Matrix metalloproteinases and their expression in mammary gland. Cell Res 1998, 8:187-194.

23. Xu D, Suenaga N, Edelmann MJ, Fridman R, Muschel RJ, Kessler BM: Novel MMP-9 substrates in cancer cells revealed by a label-free quantitative proteomics approach. Mol Cell Proteomics 2008, 7:2215-2228.

24. Padua D, Massague J: Roles of TGFbeta in metastasis. Cell Res 2009 19:89-102.

25. Meng YG, Han WD, Zhao YL, Huang K, Si YL, Wu ZQ, Mu YM: Induction of the LRP16 gene by estrogen promotes the invasive growth of Ishikawa human endometrial cancer cells through the downregulation of E-cadherin. Cell Res 2007, 17:869-880.

26. Xu J, Lamouille S, Derynck R: TGF-beta-induced epithelial to mesenchymal transition. Cell Res 2009, 19:156-172.

27. Yang J, Eddy JA, Pan Y, Hategan A, Tabus I, Wang Y, Cogdell D, Price ND Pollock RE, Lazar AJ, Hunt KK, Trent JC, Zhang W: Integrated proteomics and genomics analysis reveals a novel mesenchymal to epithelial reverting transition in leiomyosarcoma through regulation of slug. $\mathrm{Mol}$ Cell Proteomics 2010, 9:2405-2413.

28. Sitohy B, Nagy JA, Dvorak HF: Anti-VEGF/VEGFR therapy for cancer: reassessing the target. Cancer Res 2012, 72:1909-1914.

29. Chang SH, Kanasaki K, Gocheva V, Blum G, Harper J, Moses MA, Shih SC, Nagy JA, Joyce J, Bogyo M, Kalluri R, Dvorak HF: VEGF-A induces angiogenesis by perturbing the cathepsin-cysteine protease inhibitor balance in venules, causing basement membrane degradation and mother vessel formation. Cancer Res 2009, 69:4537-4544.

30. Kulasingam V, Diamandis EP: Proteomics analysis of conditioned media from three breast cancer cell lines: a mine for biomarkers and therapeutic targets. Mol Cell Proteomics 2007, 6:1997-2011.

31. Huang $Y$, Hua K, Zhou X, Jin H, Chen X, Lu X, Yu Y, Zha X, Feng Y: Activation of the PI3K/AKT pathway mediates FSH-stimulated VEGF expression in ovarian serous cystadenocarcinoma. Cell Res 2008, 18:780-791.

32. Roudnicky F, Poyet C, Wild P, Krampitz S, Negrini F, Huggenberger R, Rogler A, Stohr R, Hartmann A, Provenzano M, Otto VI, Detmar M: Endocan is upregulated on tumor vessels in invasive bladder cancer where it mediates VEGF-A-induced angiogenesis. Cancer Res 2013, 73:1097-1106.

33. Yen CJ, Lin YJ, Yen CS, Tsai HW, Tsai TF, Chang KY, Huang WC, Lin PW, Chiang CW, Chang TT: Hepatitis B virus $X$ protein upregulates mTOR signaling through IKKbeta to increase cell proliferation and VEGF production in hepatocellular carcinoma. PLoS One 2012, 7:e41931.

34. Poli V: The role of C/EBP isoforms in the control of inflammatory and native immunity functions. J Biol Chem 1998, 273:29279-29282.

35. Sebastian T, Johnson PF: RasV12-mediated down-regulation of CCAAT/ enhancer binding protein beta in immortalized fibroblasts requires loss of p19Arf and facilitates bypass of oncogene-induced senescence. Cancer Res 2009, 69:2588-2598.

36. Cui TX, Lin G, LaPensee CR, Calinescu AA, Rathore M, Streeter C, Piwien-Pilipuk G, Lanning N, Jin H, Carter-Su C, Qin ZS, Schwartz J: C/EBPbeta mediates growth hormone-regulated expression of multiple target genes. $\mathrm{Mol}$ Endocrinol 2011, 25:681-693.

37. Kuilman T, Michaloglou C, Vredeveld LC, Douma S, van Doorn R, Desmet CJ, Aarden LA, Mooi WJ, Peeper DS: Oncogene-induced senescence relayed by an interleukin-dependent inflammatory network. Cell 2008 133:1019-1031.

38. Olazabal IM, Munoz JA, Rodriguez-Navas C, Alvarez L, Delgado-Baeza E, Garcia-Ruiz JP: Prolactin's role in the early stages of liver regeneration in rats. J Cell Physiol 2009, 219:626-633.

39. Montano MM, Doughman YQ, Deng H, Chaplin L, Yang J, Wang N, Zhou Q, Ward NL, Watanabe M: Mutation of the HEXIM1 gene results in defects during heart and vascular development partly through downregulation of vascular endothelial growth factor. Circ Res 2008, 102:415-422.

40. Shen K, Ji L, Gong C, Ma Y, Yang L, Fan Y, Hou M, Wang Z: Notoginsenoside $\mathrm{Ft} 1$ promotes angiogenesis via HIF-1alpha mediated VEGF secretion and the regulation of PI3K/AKT and Raf/MEK/ERK signaling pathways. Biochem Pharmacol 2012, 84:784-792.
41. Feng J, Zhang $Y$, Xing D: Low-power laser irradiation (LPLI) promotes VEGF expression and vascular endothelial cell proliferation through the activation of ERK/Sp1 pathway. Cell Signal 2012, 24:1116-1125

42. Chen RN, Huang YH, Lin YC, Yeh CT, Liang Y, Chen SL, Lin KH: Thyroid hormone promotes cell invasion through activation of furin expression in human hepatoma cell lines. Endocrinology 2008, 149:3817-3831.

43. Chen RN, Huang YH, Yeh CT, Liao CH, Lin KH: Thyroid hormone receptors suppress pituitary tumor transforming gene 1 activity in hepatoma. Cancer Res 2008, 68:1697-1706.

44. Samuels HH, Stanley F, Casanova J: Depletion of L-3,5,3'-triiodothyronine and L-thyroxine in euthyroid calf serum for use in cell culture studies of the action of thyroid hormone. Endocrinology 1979, 105:80-85.

45. Liao CH, Yeh SC, Huang YH, Chen RN, Tsai MM, Chen WJ, Chi HC, Tai PJ, Liao CJ, Wu SM, Cheng WL, Pai LM, Lin KH: Positive regulation of spondin 2 by thyroid hormone is associated with cell migration and invasion. Endocr Relat Cancer 2010, 17:99-111.

46. Wu SM, Huang YH, Lu YH, Chien LF, Yeh CT, Tsai MM, Liao CH, Chen WJ, Liao CJ, Cheng WL, Lin KH: Thyroid hormone receptor-mediated regulation of the methionine adenosyltransferase 1 gene is associated with cell invasion in hepatoma cell lines. Cell Mol Life Sci 2010, 67:1831-1843.

47. Huang YH, Lee CY, Tai PJ, Yen CC, Liao CY, Chen WJ, Liao CJ, Cheng WL, Chen RN, Wu SM, Wang CS, Lin KH: Indirect regulation of human dehydroepiandrosterone sulfotransferase family $1 \mathrm{~A}$ member 2 by thyroid hormones. Endocrinology 2006, 147:2481-2489.

48. Repesh LA: A new in vitro assay for quantitating tumor cell invasion. Invasion Metastasis 1989, 9:192-208.

doi:10.1186/1476-4598-13-162

Cite this article as: Chen et al:: Thyroid hormone enhanced human hepatoma cell motility involves brain-specific serine protease 4 activation via ERK signaling. Molecular Cancer 2014 13:162.

\section{Submit your next manuscript to BioMed Central and take full advantage of:}

- Convenient online submission

- Thorough peer review

- No space constraints or color figure charges

- Immediate publication on acceptance

- Inclusion in PubMed, CAS, Scopus and Google Scholar

- Research which is freely available for redistribution 